\title{
Biological Control of Meloidogyne incognita by Spore-forming Plant Growth-promoting Rhizobacteria on Cotton
}

Ni Xiang, Kathy S. Lawrence, Joseph W. Kloepper, Patricia A. Donald, and John A. McInroy, Department of Entomology and Plant Pathology, Auburn University, Auburn, AL 36849; and Gary W. Lawrence, Department of Biochemistry, Molecular Biology, Entomology and Plant Pathology, Mississippi State University, Mississippi State 39762

\begin{abstract}
In the past decade, increased attention has been placed on biological control of plant-parasitic nematodes using various fungi and bacteria. The objectives of this study were to evaluate the potential of 662 plant growth-promoting rhizobacteria (PGPR) strains for mortality to Meloidogyne incognita $\mathrm{J} 2$ in vitro and for nematode management in greenhouse, microplot, and field trials. Results indicated that the mortality of $M$. incognita $\mathrm{J} 2$ by the PGPR strains ranged from 0 to $100 \%$ with an average of $39 \%$. Among the PGPR strains examined, 212 of 662 strains (or 33\%) caused significantly greater mortality percent of $M$. incognita $\mathrm{J} 2$ than the untreated control. Bacillus was the major genus initiating a greater mortality percentage when compared with the other genera. In subsequent trials, B. velezensis strain Bve2 reduced

$M$. incognita eggs per gram of cotton root in the greenhouse trials at 45 days after planting (DAP) similarly to the commercial standards Abamectin and Clothianidin plus B. firmus I-1582. Bacillus mojavensis strain Bmo3, B. velezensis strain Bve2, B. subtilis subsp. subtilis strain Bsssu3, and the Mixture 2 (Abamectin $+\mathrm{Bve} 2+B$. altitudinis strain Bal13) suppressed $M$. incognita eggs per gram of root in the microplot at 45 DAP. Bacillus velezensis strains Bve 2 and Bve12 also increased seed-cotton yield in the microplot and field trials. Overall, results indicate that $B$. velezensis strains Bve 2 and Bve $12, B$. mojavensis strain Bmo3, and Mixture 2 have potential to reduce $M$. incognita population density and to enhance growth of cotton when applied as in-furrow sprays at planting.
\end{abstract}

Meloidogyne incognita (Kofoid \& White) Chitwood, the southern root-knot nematode, is one of the most important plant-parasitic nematodes affecting cotton (Gossypium hirsutum) production in the United States (Creech et al. 1995; Robinson 2007). In 2015, cotton yield in the United States was estimated to be 7.9 million bales, but losses due to $M$. incognita were estimated at 215,500 bales, which was equivalent to $1.35 \%$ of total production (Lawrence et al. 2016). Due to environmental and health concerns with the use of chemical nematicides for nematode management, many alternative strategies such as biological agents for plant-parasitic nematode control have been investigated (Burkett-Cadena et al. 2008; Kiewnick and Sikora 2006). Plant growth-promoting rhizobacteria (PGPR) promote plant growth and elicit significant reductions in the incidence or severity of various diseases on a diversity of hosts (Kloepper et al. 2004). Strains of PGPR that also exhibit nematicidal activity and/or elicit induced systemic plant resistance to plant-parasitic nematodes could be potential alternatives to chemical nematicides.

Many studies have reported antagonistic activity of various bacterial strains of Bacillus spp. against plant-parasitic nematodes. Twelve species of Bacillus have been documented for M. incognita management, including B. amyloliquefaciens (syn. B. velezensis) (Burkett-Cadena et al. 2008), B. cereus (Siddiqui and Mahmood 1999), B. circulans, B. coagulans (Serfoji et al. 2010), B. firmus (Mendoza et al. 2008; Terefe et al. 2009), B. licheniformis (Siddiqui and Husain 1991; Siddiqui and Mahmood 1992), B. megaterium (Kloepper et al. 1992), B. polymyxa (Khan and Akram 2000), B. sphaericus (Krechel et al. 2002), B. subtilis (Kavitha et al. 2007; Siddiqui and Mahmood 1999), and B. thuringiensis (Mohammed

Current address of K. S. Lawrence: Department of Entomology and Plant Pathology, Auburn University, Auburn, AL 36849.

Corresponding author: K. S. Lawrence; E-mail: lawrekk@auburn.edu

Accepted for publication 2 December 2016.

This article is in the public domain and not copyrightable. It may be freely reprinted with customary crediting of the source. The American Phytopathological Society, 2017. et al. 2008; Zuckerman et al. 1993). Among these Bacillus spp., some have been developed into commercial products for controlling plant disease and nematodes. BioNem-WP/BioSafe, a $B$. firmus product developed by AgroGreen, was reported effective against M. incognita, M. hapla, Heterodera spp., Tylenchulus semipenetrans, Xiphinema index, and Ditylenchus dipsaci (Keren-Zur et al. 2000). BioYield, a combination of B. velezensis strain IN937a and $B$. subtilis strain GB03, was developed by Gustafson in a flowable formulation for management of soil-borne pathogens and suppression of $M$. incognita population density on tomato (Burkett-Cadena et al. 2008; Kloepper et al. 2004). Nemix, a Bacillus spp. product developed by AgriLife/Chr. Hansen, was reported for control of root-knot nematodes on vegetables and fruit trees (Hallmann et al. 2009). VOTiVO, Bacillus firmus GB-126, is marketed by Bayer CropScience as a seed treatment for the control of plant-parasitic nematodes on corn, cotton, sorghum, soybean, and sugar beet (Wilson and Jackson 2013). Pathway Consortia, a product containing B. subtilis, $B$. licheniformis, B. megaterium, B. coagulans, Pseudomonas fluorescens, Streptomyces spp., and Trichoderma spp. developed by Pathway Holdings, was reported for the management of plant-parasitic nematodes (Askary 2015).

Modes of action for biocontrol of plant-parasitic nematodes of some Bacillus strains have been studied. Mendoza et al. (2008) studied invitro activity of $B$. firmus against burrowing nematode Radopholus similis, root-knot nematode $M$. incognita, and stem nematode Ditylenchus dipsaci, and detected rates of mortality of these nematodes and significant reduction of $M$. incognita hatching after incubation with a low concentration of pure culture filtrates. The mode of action for the observed nematode paralysis and mortality was attributed to secondary metabolites produced by the bacteria (Mendoza et al. 2008).

Induced systemic resistance (ISR) caused by some Bacillus strains has been documented. Sikora (1988) found that B. subtilis can induce protection against $M$. incognita in cotton. Kloepper et al. (2004) reported that specific strains of $B$. velezensis, B. cereus, B. mycoides, B. pasteurii, B. pumilus, B. sphaericus, and B. subtilis can elicit significant reductions in the incidence or severity of various diseases on a diversity of hosts through ISR. Schrimsher (2013) studied the ISR of $B$. firmus GB-126 against Heterodera glycines and M. incognita in split-root experiments in the greenhouse and found that ISR was evident in the $H$. glycines split-root assay but not in the $M$. incognita 
Table 1. Effect of plant growth-promoting rhizobacteria strains on Meloidogyne incognita $\mathbf{J} 2$ mortality percentage higher than untreated control in laboratory trials

\begin{tabular}{|c|c|c|c|c|c|}
\hline \multirow[b]{2}{*}{ Code } & \multirow[b]{2}{*}{ Scientific name } & \multirow{2}{*}{$\begin{array}{l}\text { Meloidogyne incognita } \\
\text { J2 mortality }(\%)^{\mathbf{b}}\end{array}$} & \multicolumn{3}{|c|}{ Dunnett's $P$ versus ${ }^{c}(P \leq 0.05)$} \\
\hline & & & Clothianidin + B. firmus & Aldicarb $^{d}$ & Water \\
\hline$\overline{A d 1}$ & Arthrobacter defluvii & 53.5 & 0.8886 & 0.0681 & 0.0150 \\
\hline $\mathrm{Bal} 2$ & Bacillus altitudinis & 71.1 & 0.0535 & 0.9365 & $<0.0001$ \\
\hline Bal3 & Bacillus altitudinis & 96.4 & $<0.0001$ & 1.0000 & $<0.0001$ \\
\hline Bal4 & Bacillus altitudinis & 97.4 & $<0.0001$ & 1.0000 & $<0.0001$ \\
\hline Bal5 & Bacillus altitudinis & 100.0 & $<0.0001$ & 1.0000 & $<0.0001$ \\
\hline Bal11 & Bacillus altitudinis & 59.7 & 0.9047 & 0.6812 & 0.0483 \\
\hline Bal12 & Bacillus altitudinis & 52.5 & 0.9375 & 0.0531 & 0.0201 \\
\hline Bal13 & Bacillus altitudinis & 75.9 & 0.1480 & 1.0000 & 0.0009 \\
\hline Bal14 & Bacillus altitudinis & 87.7 & 0.0003 & 1.0000 & $<0.0001$ \\
\hline Bal15 & Bacillus altitudinis & 94.5 & $<0.0001$ & 1.0000 & $<0.0001$ \\
\hline Bal16 & Bacillus altitudinis & 61.3 & 0.3699 & 0.3157 & 0.0013 \\
\hline Bal17 & Bacillus altitudinis & 84.4 & 0.0010 & 1.0000 & $<0.0001$ \\
\hline Bar6 & Bacillus aryabhattai & 78.2 & 0.0077 & 1.0000 & $<0.0001$ \\
\hline Bar7 & Bacillus aryabhattai & 75.1 & 0.0193 & 0.9992 & $<0.0001$ \\
\hline Bar8 & Bacillus aryabhattai & 88.1 & 0.0003 & 1.0000 & $<0.0001$ \\
\hline Bar9 & Bacillus aryabhattai & 79.4 & 0.0054 & 1.0000 & $<0.0001$ \\
\hline Bar14 & Bacillus aryabhattai & 63.3 & 0.2694 & 0.4263 & 0.0006 \\
\hline Bar15 & Bacillus aryabhattai & 64.6 & 0.2131 & 0.5124 & 0.0004 \\
\hline Bar16 & Bacillus aryabhattai & 67.8 & 0.4568 & 0.9930 & 0.0078 \\
\hline Bar17 & Bacillus aryabhattai & 60.3 & 0.4294 & 0.2671 & 0.0018 \\
\hline Bar19 & Bacillus aryabhattai & 87.6 & 0.0003 & 1.0000 & $<0.0001$ \\
\hline Bar20 & Bacillus aryabhattai & 86.8 & 0.0004 & 1.0000 & $<0.0001$ \\
\hline Bar21 & Bacillus aryabhattai & 90.8 & $<0.0001$ & 1.0000 & $<0.0001$ \\
\hline Bar22 & Bacillus aryabhattai & 88.3 & 0.0002 & 1.0000 & $<0.0001$ \\
\hline Bar24 & Bacillus aryabhattai & 55.8 & 0.7464 & 0.1116 & 0.0078 \\
\hline Bar25 & Bacillus aryabhattai & 54.1 & 0.8589 & 0.0768 & 0.0129 \\
\hline Bar27 & Bacillus aryabhattai & 100.0 & $<0.0001$ & 1.0000 & $<0.0001$ \\
\hline Bar28 & Bacillus aryabhattai & 95.4 & $<0.0001$ & 1.0000 & $<0.0001$ \\
\hline Bar29 & Bacillus aryabhattai & 96.7 & $<0.0001$ & 1.0000 & $<0.0001$ \\
\hline Bar31 & Bacillus aryabhattai & 68.5 & 0.0971 & 0.7917 & $<0.0001$ \\
\hline Bar32 & Bacillus aryabhattai & 62.8 & 0.2907 & 0.3990 & 0.0007 \\
\hline Bar33 & Bacillus aryabhattai & 83.5 & 0.0014 & 1.0000 & $<0.0001$ \\
\hline Bar41 & Bacillus aryabhattai & 97.6 & 0.0011 & 1.0000 & $<0.0001$ \\
\hline Bar46 & Bacillus aryabhattai & 84.2 & 0.0315 & 1.0000 & $<0.0001$ \\
\hline Bar47 & Bacillus aryabhattai & 57.8 & 0.5981 & 0.1692 & 0.0041 \\
\hline Bar49 & Bacillus aryabhattai & 66.7 & 0.1423 & 0.6615 & 0.0002 \\
\hline Bce4 & Bacillus cereus & 71.1 & 0.0538 & 0.9355 & $<0.0001$ \\
\hline Bce6 & Bacillus cereus & 73.7 & 0.0275 & 0.9940 & $<0.0001$ \\
\hline Bce7 & Bacillus cereus & 56.8 & 0.6688 & 0.1395 & 0.0056 \\
\hline Bce8 & Bacillus cereus & 94.3 & $<0.0001$ & 1.0000 & $<0.0001$ \\
\hline Bce14 & Bacillus cereus & 79.3 & 0.0056 & 1.0000 & $<0.0001$ \\
\hline Bce15 & Bacillus cereus & 64.6 & 0.2121 & 0.5141 & 0.0004 \\
\hline Bce37 & Bacillus cereus & 51.0 & 0.9798 & 0.0369 & 0.0298 \\
\hline Bce38 & Bacillus cereus & 61.7 & 0.3489 & 0.3354 & 0.0011 \\
\hline Bce41 & Bacillus cereus & 73.3 & 0.0312 & 0.9895 & $<0.0001$ \\
\hline Bce42 & Bacillus cereus & 94.2 & $<0.0001$ & 1.0000 & $<0.0001$ \\
\hline Bce44 & Bacillus cereus & 79.1 & 0.0059 & 1.0000 & $<0.0001$ \\
\hline Bce45 & Bacillus cereus & 70.9 & 0.0564 & 0.9272 & $<0.0001$ \\
\hline Bce46 & Bacillus cereus & 94.3 & $<0.0001$ & 1.0000 & $<0.0001$ \\
\hline Bce47 & Bacillus cereus & 50.3 & 0.9898 & 0.0310 & 0.0355 \\
\hline $\mathrm{Bmt} 2$ & Bacillus methylotrophicus & 76.7 & 0.0120 & 1.0000 & $<0.0001$ \\
\hline $\mathrm{Bmt5}$ & Bacillus methylotrophicus & 90.7 & $<0.0001$ & 1.0000 & $<0.0001$ \\
\hline Bmt7 & Bacillus methylotrophicus & 82.3 & 0.0021 & 1.0000 & $<0.0001$ \\
\hline $\mathrm{Bmt9}$ & Bacillus methylotrophicus & 68.1 & 0.1058 & 0.7640 & $<0.0001$ \\
\hline $\mathrm{Bmo} 2$ & Bacillus mojavensis & 49.9 & 0.9940 & 0.0275 & 0.0398 \\
\hline \multirow[t]{2}{*}{ Bmo3 } & Bacillus mojavensis & 70.6 & 0.3255 & 0.9998 & 0.0039 \\
\hline & & & & \multicolumn{2}{|c|}{ (continued on next page) } \\
\hline
\end{tabular}

a In-vitro tests were performed in 96-well plates. Data of 212 PGPR strains indicating significantly higher mortality on $M$. incognita J2 than untreated control were presented in the table. All the PGPR strains had four replications and controls were based on 17 repeats. Data collected were analyzed in SAS 9.4 using PROC GLIMMIX procedure at significance level of $\alpha \leq 0.05 . P$ value less than 0.05 indicate a significant effect. LS-means and adjusted $P$ values were presented in the table.

b Mortality percentage was determined by the following equation: [(live $\mathrm{J} 2$ prior to exposure - live $\mathrm{J} 2$ at 48 hours) / live $\mathrm{J} 2$ prior to exposure] $\times 100$.

${ }^{c}$ Dunnett's option was used in the LS-means statement to assess the differences between bacterial strains and the Poncho/Votivo, Temik, and the untreated control.

d Active ingredients for Poncho/Votivo are Clothianidin plus B. firmus I-1582, Temik is Aldicarb, and untreated control is sterile distilled water.

e Indistinguishable species and unidentified strains. 
Table 1. (continued from preceding page)

\begin{tabular}{|c|c|c|c|c|c|}
\hline \multirow[b]{2}{*}{ Code } & \multirow[b]{2}{*}{ Scientific name } & \multirow{2}{*}{$\begin{array}{l}\text { Meloidogyne incognita } \\
\text { J2 mortality }(\%)^{\mathbf{b}}\end{array}$} & \multicolumn{3}{|c|}{ Dunnett's $P$ versus ${ }^{c}(P \leq 0.05)$} \\
\hline & & & Clothianidin $+B$. firmus & Aldicarbd $^{d}$ & Water \\
\hline $\mathrm{Bmo} 4$ & Bacillus mojavensis & 66.8 & 0.1402 & 0.6670 & 0.0002 \\
\hline Bmy1 & Bacillus mycoides & 75.9 & 0.0154 & 0.9998 & $<0.0001$ \\
\hline Bmy16 & Bacillus mycoides & 55.3 & 0.7762 & 0.1019 & 0.0089 \\
\hline Bmy17 & Bacillus mycoides & 71.1 & 0.0531 & 0.9375 & $<0.0001$ \\
\hline Bmy18 & Bacillus mycoides & 85.4 & 0.0007 & 1.0000 & $<0.0001$ \\
\hline Bmy20 & Bacillus mycoides & 67.8 & 0.1122 & 0.7446 & 0.0001 \\
\hline Bmy 25 & Bacillus mycoides & 54.4 & 0.8406 & 0.0822 & 0.0118 \\
\hline Bmy26 & Bacillus mycoides & 70.0 & 0.0693 & 0.8845 & $<0.0001$ \\
\hline Bmy30 & Bacillus mycoides & 94.9 & $<0.0001$ & 1.0000 & $<0.0001$ \\
\hline Bmy34 & Bacillus mycoides & 54.3 & 0.8453 & 0.0808 & 0.0121 \\
\hline Bmy36 & Bacillus mycoides & 58.9 & 0.5226 & 0.2073 & 0.0029 \\
\hline Bps4 & Bacillus psychrosaccharolyticus & 75.1 & 0.0193 & 0.9992 & $<0.0001$ \\
\hline Bpu5 & Bacillus pumilus & 79.1 & 0.0059 & 1.0000 & $<0.0001$ \\
\hline Bpu6 & Bacillus pumilus & 60.0 & 0.8922 & 0.6990 & 0.0454 \\
\hline Bsa1 & Bacillus safensis & 96.8 & $<0.0001$ & 1.0000 & $<0.0001$ \\
\hline Bsa4 & Bacillus safensis & 66.0 & 0.1643 & 0.6089 & 0.0002 \\
\hline Bsa6 & Bacillus safensis & 92.9 & $<0.0001$ & 1.0000 & $<0.0001$ \\
\hline Bsa7 & Bacillus safensis & 87.9 & 0.0003 & 1.0000 & $<0.0001$ \\
\hline Bsa8 & Bacillus safensis & 100.0 & $<0.0001$ & 1.0000 & $<0.0001$ \\
\hline Bsa9 & Bacillus safensis & 53.7 & 0.8804 & 0.0705 & 0.0144 \\
\hline Bsa12 & Bacillus safensis & 90.2 & 0.0001 & 1.0000 & $<0.0001$ \\
\hline Bsa26 & Bacillus safensis & 64.6 & 0.6376 & 0.9319 & 0.0167 \\
\hline Bsa28 & Bacillus safensis & 56.9 & 0.6651 & 0.1409 & 0.0055 \\
\hline Bsa31 & Bacillus safensis & 64.9 & 0.2007 & 0.5346 & 0.0003 \\
\hline Bsa34 & Bacillus safensis & 64.4 & 0.2220 & 0.4972 & 0.0004 \\
\hline Bsa35 & Bacillus safensis & 96.5 & $<0.0001$ & 1.0000 & $<0.0001$ \\
\hline Bsp2 & Bacillus simplex & 82.0 & 0.0023 & 1.0000 & $<0.0001$ \\
\hline Bsp13 & Bacillus simplex & 65.1 & 0.1942 & 0.5468 & 0.0003 \\
\hline Bsp24 & Bacillus simplex & 76.2 & 0.0139 & 0.9999 & $<0.0001$ \\
\hline Bsp32 & Bacillus simplex & 75.7 & 0.0161 & 0.9998 & $<0.0001$ \\
\hline Bsp33 & Bacillus simplex & 65.5 & 0.1801 & 0.5749 & 0.0003 \\
\hline Bsp35 & Bacillus simplex & 81.6 & 0.0027 & 1.0000 & $<0.0001$ \\
\hline Bsp36 & Bacillus simplex & 68.4 & 0.0986 & 0.7865 & $<0.0001$ \\
\hline Bsp42 & Bacillus simplex & 79.0 & 0.0061 & 1.0000 & $<0.0001$ \\
\hline Bsp44 & Bacillus simplex & 66.0 & 0.1643 & 0.6089 & 0.0002 \\
\hline Bsp45 & Bacillus simplex & 58.0 & 0.5856 & 0.1750 & 0.0039 \\
\hline Bsp46 & Bacillus simplex & 55.8 & 0.7429 & 0.1128 & 0.0077 \\
\hline Bsp47 & Bacillus simplex & 74.9 & 0.0199 & 0.9990 & $<0.0001$ \\
\hline Bsp48 & Bacillus simplex & 71.0 & 0.0172 & 0.7796 & $<0.0001$ \\
\hline Bsp50 & Bacillus simplex & 83.0 & 0.0017 & 1.0000 & $<0.0001$ \\
\hline Bsp51 & Bacillus simplex & 75.5 & 0.0170 & 0.9996 & $<0.0001$ \\
\hline Bsp52 & Bacillus simplex & 76.9 & 0.0116 & 1.0000 & $<0.0001$ \\
\hline Bsp53 & Bacillus simplex & 82.7 & 0.0426 & 1.0000 & 0.0001 \\
\hline Bsp54 & Bacillus simplex & 83.1 & 0.0016 & 1.0000 & $<0.0001$ \\
\hline Bsp55 & Bacillus simplex & 81.1 & 0.0031 & 1.0000 & $<0.0001$ \\
\hline Bsp56 & Bacillus simplex & 75.3 & 0.0179 & 0.9995 & $<0.0001$ \\
\hline Bsp57 & Bacillus simplex & 83.2 & 0.0016 & 1.0000 & $<0.0001$ \\
\hline Bsp58 & Bacillus simplex & 88.3 & 0.0002 & 1.0000 & $<0.0001$ \\
\hline Bsp59 & Bacillus simplex & 83.7 & 0.0013 & 1.0000 & $<0.0001$ \\
\hline Bsp60 & Bacillus simplex & 64.3 & 0.2240 & 0.4939 & 0.0004 \\
\hline Bsp61 & Bacillus simplex & 84.8 & 0.0009 & 1.0000 & $<0.0001$ \\
\hline Bsp62 & Bacillus simplex & 69.5 & 0.0773 & 0.8574 & $<0.0001$ \\
\hline Bsp63 & Bacillus simplex & 76.4 & 0.0132 & 1.0000 & $<0.0001$ \\
\hline Bsp64 & Bacillus simplex & 89.2 & $<0.0001$ & 1.0000 & $<0.0001$ \\
\hline Bsp66 & Bacillus simplex & 70.9 & 0.0568 & 0.9261 & $<0.0001$ \\
\hline Bsp69 & Bacillus simplex & 51.2 & 0.9764 & 0.0385 & 0.0285 \\
\hline Bsp79 & Bacillus simplex & 76.8 & 0.0117 & 1.0000 & $<0.0001$ \\
\hline Bsp81 & Bacillus simplex & 86.1 & 0.0006 & 1.0000 & $<0.0001$ \\
\hline Bsp82 & Bacillus simplex & 73.5 & 0.0292 & 0.9921 & $<0.0001$ \\
\hline Bsp84 & Bacillus simplex & 99.6 & 0.0006 & 1.0000 & $<0.0001$ \\
\hline Bsp87 & Bacillus simplex & 81.3 & 0.0568 & 1.0000 & 0.0002 \\
\hline Bsp88 & Bacillus simplex & 91.5 & $<0.0001$ & 1.0000 & $<0.0001$ \\
\hline Bsp89 & Bacillus simplex & 84.3 & 0.0010 & 1.0000 & $<0.0001$ \\
\hline Bsp91 & Bacillus simplex & 64.4 & 0.2220 & 0.4972 & 0.0004 \\
\hline \multirow[t]{2}{*}{ Bsp92 } & Bacillus simplex & 90.2 & 0.0001 & 1.0000 & $<0.0001$ \\
\hline & & & & \multicolumn{2}{|c|}{ (continued on next page) } \\
\hline
\end{tabular}


Table 1. (continued from preceding page)

\begin{tabular}{|c|c|c|c|c|c|}
\hline \multirow[b]{2}{*}{ Code } & \multirow[b]{2}{*}{ Scientific name } & \multirow{2}{*}{$\begin{array}{c}\text { Meloidogyne incognita } \\
\text { J2 mortality }(\%)^{\mathbf{b}}\end{array}$} & \multicolumn{3}{|c|}{ Dunnett's $P$ versus $^{c}(P \leq 0.05)$} \\
\hline & & & Clothianidin + B. firmus & Aldicarb $^{d}$ & Water \\
\hline Bsp93 & Bacillus simplex & 56.1 & 0.7196 & 0.1208 & 0.0070 \\
\hline Bsp94 & Bacillus simplex & 81.3 & 0.0029 & 1.0000 & $<0.0001$ \\
\hline Bsp96 & Bacillus simplex & 95.5 & $<0.0001$ & 1.0000 & $<0.0001$ \\
\hline Bsp101 & Bacillus simplex & 98.0 & 0.0010 & 1.0000 & $<0.0001$ \\
\hline Bsp114 & Bacillus simplex & 99.9 & 0.0006 & 1.0000 & $<0.0001$ \\
\hline Bsp115 & Bacillus simplex & 99.9 & 0.0006 & 1.0000 & $<0.0001$ \\
\hline Bsp116 & Bacillus simplex & 99.1 & 0.0007 & 1.0000 & $<0.0001$ \\
\hline Bsp118 & Bacillus simplex & 69.3 & 0.0818 & 0.8422 & $<0.0001$ \\
\hline Bsp123 & Bacillus simplex & 83.7 & 0.0350 & 1.0000 & $<0.0001$ \\
\hline Bsp124 & Bacillus simplex & 67.5 & 0.1195 & 0.7232 & 0.0001 \\
\hline Bsp126 & Bacillus simplex & 76.2 & 0.0142 & 0.9999 & $<0.0001$ \\
\hline Bsp131 & Bacillus simplex & 88.2 & 0.0003 & 1.0000 & $<0.0001$ \\
\hline Bsp134 & Bacillus simplex & 62.9 & 0.2847 & 0.4064 & 0.0007 \\
\hline Bsp135 & Bacillus simplex & 71.4 & 0.0497 & 0.9477 & $<0.0001$ \\
\hline Bsp143 & Bacillus simplex & 98.2 & 0.0009 & 1.0000 & $<0.0001$ \\
\hline Bsp154 & Bacillus simplex & 99.9 & 0.0006 & 1.0000 & $<0.0001$ \\
\hline Bsp187 & Bacillus simplex & 67.7 & 0.1146 & 0.7375 & 0.0001 \\
\hline Bsp195 & Bacillus simplex & 90.0 & 0.0001 & 1.0000 & $<0.0001$ \\
\hline Bsp197 & Bacillus simplex & 64.3 & 0.2240 & 0.4939 & 0.0004 \\
\hline Bsp198 & Bacillus simplex & 80.6 & 0.0037 & 1.0000 & $<0.0001$ \\
\hline Bsp199 & Bacillus simplex & 52.8 & 0.9251 & 0.0571 & 0.0185 \\
\hline Bsp200 & Bacillus simplex & 71.9 & 0.0437 & 0.9643 & $<0.0001$ \\
\hline Bssin 8 & Bacillus subtilis subsp. inaquosorum & 88.4 & 0.0002 & 1.0000 & $<0.0001$ \\
\hline Bssin 9 & Bacillus subtilis subsp. inaquosorum & 94.6 & $<0.0001$ & 1.0000 & $<0.0001$ \\
\hline Bssin 10 & Bacillus subtilis subsp. inaquosorum & 94.6 & $<0.0001$ & 1.0000 & $<0.0001$ \\
\hline Bssin 11 & Bacillus subtilis subsp. inaquosorum & 54.1 & 0.8544 & 0.0781 & 0.0126 \\
\hline Bssin 12 & Bacillus subtilis subsp. inaquosorum & 94.3 & $<0.0001$ & 1.0000 & $<0.0001$ \\
\hline Bssin 14 & Bacillus subtilis subsp. inaquosorum & 94.5 & $<0.0001$ & 1.0000 & $<0.0001$ \\
\hline Bssin 15 & Bacillus subtilis subsp. inaquosorum & 90.6 & $<0.0001$ & 1.0000 & $<0.0001$ \\
\hline Bsssu2 & Bacillus subtilis subsp. subtilis & 84.4 & 0.0302 & 1.0000 & $<0.0001$ \\
\hline Bsssu3 & Bacillus subtilis subsp. subtilis & 82.4 & 0.0457 & 1.0000 & 0.0001 \\
\hline Bte2 & Bacillus tequilensis & 93.5 & $<0.0001$ & 1.0000 & $<0.0001$ \\
\hline Bth2 & Bacillus thuringiensis & 58.8 & 0.5312 & 0.2026 & 0.0030 \\
\hline Bto18 & Bacillus toyonensis & 87.5 & 0.0003 & 1.0000 & $<0.0001$ \\
\hline Bto21 & Bacillus toyonensis & 63.5 & 0.2603 & 0.4387 & 0.0006 \\
\hline Bto22 & Bacillus toyonensis & 82.9 & 0.0017 & 1.0000 & $<0.0001$ \\
\hline Bto23 & Bacillus toyonensis & 73.3 & 0.0310 & 0.9898 & $<0.0001$ \\
\hline Bto24 & Bacillus toyonensis & 76.8 & 0.0118 & 1.0000 & $<0.0001$ \\
\hline Bto34 & Bacillus toyonensis & 74.0 & 0.0258 & 0.9957 & $<0.0001$ \\
\hline Bto36 & Bacillus toyonensis & 93.1 & $<0.0001$ & 1.0000 & $<0.0001$ \\
\hline Bto40 & Bacillus toyonensis & 98.5 & $<0.0001$ & 1.0000 & $<0.0001$ \\
\hline Bto45 & Bacillus toyonensis & 82.1 & 0.0022 & 1.0000 & $<0.0001$ \\
\hline Bto46 & Bacillus toyonensis & 64.2 & 0.2271 & 0.4889 & 0.0004 \\
\hline Bto49 & Bacillus toyonensis & 66.2 & 0.1572 & 0.6252 & 0.0002 \\
\hline Bto51 & Bacillus toyonensis & 87.2 & 0.0004 & 1.0000 & $<0.0001$ \\
\hline Bto52 & Bacillus toyonensis & 89.4 & 0.0002 & 1.0000 & $<0.0001$ \\
\hline Bto53 & Bacillus toyonensis & 75.6 & 0.0167 & 0.9997 & $<0.0001$ \\
\hline Bto54 & Bacillus toyonensis & 81.3 & 0.0029 & 1.0000 & $<0.0001$ \\
\hline Bto55 & Bacillus toyonensis & 91.3 & $<0.0001$ & 1.0000 & $<0.0001$ \\
\hline Bto57 & Bacillus toyonensis & 87.0 & 0.0004 & 1.0000 & $<0.0001$ \\
\hline Bto58 & Bacillus toyonensis & 81.0 & 0.0032 & 1.0000 & $<0.0001$ \\
\hline Bto59 & Bacillus toyonensis & 68.3 & 0.1019 & 0.7762 & $<0.0001$ \\
\hline Bto61 & Bacillus toyonensis & 91.3 & $<0.0001$ & 1.0000 & $<0.0001$ \\
\hline Bto63 & Bacillus toyonensis & 84.5 & 0.0010 & 1.0000 & $<0.0001$ \\
\hline Bto64 & Bacillus toyonensis & 66.6 & 0.1445 & 0.6560 & 0.0002 \\
\hline Bto65 & Bacillus toyonensis & 86.6 & 0.0004 & 1.0000 & $<0.0001$ \\
\hline Bto66 & Bacillus toyonensis & 72.3 & 0.0398 & 0.9737 & $<0.0001$ \\
\hline Bve2 & Bacillus velezensis & 72.8 & 0.2386 & 1.0000 & 0.0021 \\
\hline Bve4 & Bacillus velezensis & 54.1 & 0.8559 & 0.0777 & 0.0127 \\
\hline Bve5 & Bacillus velezensis & 54.7 & 0.8216 & 0.0879 & 0.0108 \\
\hline Bve12 & Bacillus velezensis & 81.1 & 0.0591 & 1.0000 & 0.0002 \\
\hline Bve13 & Bacillus velezensis & 61.9 & 0.7951 & 0.8106 & 0.0303 \\
\hline Bve14 & Bacillus velezensis & 89.3 & 0.0099 & 1.0000 & $<0.0001$ \\
\hline Bve21 & Bacillus velezensis & 52.4 & 0.9423 & 0.0516 & 0.0208 \\
\hline \multirow[t]{2}{*}{ Bve28 } & Bacillus velezensis & 60.9 & 0.3960 & 0.2932 & 0.0015 \\
\hline & & & & \multicolumn{2}{|c|}{ (continued on next page) } \\
\hline
\end{tabular}


Table 1. (continued from preceding page)

\begin{tabular}{|c|c|c|c|c|c|}
\hline \multirow[b]{2}{*}{ Code } & \multirow[b]{2}{*}{ Scientific name } & \multirow{2}{*}{$\begin{array}{l}\text { Meloidogyne incognita } \\
\text { J2 mortality }(\%)^{\mathbf{b}}\end{array}$} & \multicolumn{3}{|c|}{ Dunnett's $P$ versus ${ }^{c}(P \leq 0.05)$} \\
\hline & & & Clothianidin + B. firmus & Aldicarb $^{d}$ & $\overline{\text { Water }}$ \\
\hline Bve34 & Bacillus velezensis & 58.9 & 0.7050 & 0.3464 & 0.0108 \\
\hline Bve37 & Bacillus velezensis & 76.5 & 0.1352 & 1.0000 & 0.0007 \\
\hline Bve40 & Bacillus velezensis & 76.5 & 0.1341 & 1.0000 & 0.0007 \\
\hline Bwe2 & Bacillus weihenstephanensis & 83.6 & 0.0013 & 1.0000 & $<0.0001$ \\
\hline Bwe5 & Bacillus weihenstephanensis & 57.8 & 0.5999 & 0.1684 & 0.0042 \\
\hline Bwe10 & Bacillus weihenstephanensis & 94.3 & $<0.0001$ & 1.0000 & $<0.0001$ \\
\hline Bwe15 & Bacillus weihenstephanensis & 75.4 & 0.0174 & 0.9996 & $<0.0001$ \\
\hline Bwe16 & Bacillus weihenstephanensis & 81.8 & 0.0025 & 1.0000 & $<0.0001$ \\
\hline Brio1 & Brevibacterium iodinum & 87.8 & 0.0003 & 1.0000 & $<0.0001$ \\
\hline Fso1 & Fictibacillus solisalsi & 70.3 & 0.3385 & 0.9997 & 0.0042 \\
\hline Lma1 & Lysinibacillus macroides & 64.8 & 0.6287 & 0.9368 & 0.0161 \\
\hline Paam2 & Paenibacillus amylolyticus & 58.0 & 0.5838 & 0.1758 & 0.0039 \\
\hline Paam3 & Paenibacillus amylolyticus & 58.3 & 0.5608 & 0.1871 & 0.0035 \\
\hline Paam6 & Paenibacillus amylolyticus & 70.8 & 0.0574 & 0.9240 & $<0.0001$ \\
\hline Paam7 & Paenibacillus amylolyticus & 82.8 & 0.0018 & 1.0000 & $<0.0001$ \\
\hline Paam8 & Paenibacillus amylolyticus & 95.2 & $<0.0001$ & 1.0000 & $<0.0001$ \\
\hline Pala4 & Paenibacillus lautus & 70.4 & 0.0628 & 0.9065 & $<0.0001$ \\
\hline Patu1 & Paenibacillus tundrae & 79.6 & 0.0050 & 1.0000 & $<0.0001$ \\
\hline Paxy2 & Paenibacillus xylanexedens & 90.4 & 0.0001 & 1.0000 & $<0.0001$ \\
\hline Spg8 & Sporosarcina globispora & 84.4 & 0.0010 & 1.0000 & $<0.0001$ \\
\hline Uid4 & Bacillus aerophilus/stratosphericus ${ }^{\mathrm{e}}$ & 89.1 & 0.0002 & 1.0000 & $<0.0001$ \\
\hline Uid6 & Bacillus aerophilus/stratosphericus ${ }^{\mathrm{e}}$ & 88.2 & 0.0002 & 1.0000 & $<0.0001$ \\
\hline Uid7 & Bacillus aerophilus/stratosphericus ${ }^{\mathrm{e}}$ & 54.8 & 0.8134 & 0.0904 & 0.0104 \\
\hline Uid8 & Bacillus altitudinis/stratosphericus/aerophilus ${ }^{\mathrm{e}}$ & 98.9 & $<0.0001$ & 1.0000 & $<0.0001$ \\
\hline Uid9 & Bacillus altitudinis/stratosphericus/aerophilus ${ }^{\mathrm{e}}$ & 96.2 & $<0.0001$ & 1.0000 & $<0.0001$ \\
\hline Uid10 & Bacillus altitudinis/stratosphericus/aerophilus ${ }^{\mathrm{e}}$ & 96.8 & $<0.0001$ & 1.0000 & $<0.0001$ \\
\hline Control & Active ingredient $^{\mathrm{d}}$ & & & & \\
\hline Poncho/Votivo & Clothianidin and B. firmus I-1582 & 24.4 & $\ldots$ & $<0.0001$ & 1.0000 \\
\hline Temik & Aldicarb & 99.2 & $<0.0001$ & $\ldots$ & $<0.0001$ \\
\hline Untreated control & Sterile distilled water & 2.0 & 1.0000 & $<0.0001$ & $\ldots$ \\
\hline
\end{tabular}

split-root assay. Collectively, these studies indicate that Bacillus spp. are promising candidates for nematode disease management through diverse modes of action.

The overall goal of this research was to investigate selected PGPR strains for their potential biological control of $M$. incognita on cotton. The specific objectives were to assess the potential of PGPR strains for mortality of $M$. incognita $\mathrm{J} 2$ in vitro and evaluate the efficacy of PGPR strains for reduction of $M$. incognita population density and plant growth promotion on cotton in greenhouse and microplot trials, and in field production systems.

\section{Materials and Methods}

PGPR strains. A total of 662 PGPR strains were included in invitro studies. PGPR strains were originally isolated, identified, and stored by J. W. Kloepper at Auburn University, Auburn, AL. Among these strains, $92.7 \%$ were Bacillus spp. including 208 strains of $B$. simplex, 70 strains of $B$. toyonensis, 53 strains of $B$. aryabhattai, 51 strains of B. cereus, 44 strains of $B$. mycoides, 41 strains of $B$. velezensis, 35 strains of $B$. safensis, 21 strains of $B$. altitudinis, 21 strains of $B$. weihenstephanensis, 15 strains of $B$. subtilis subsp. inaquosorum, 13 strains of $B$. methylotrophicus, six strains of $B$. pumilus, five strains of B. psychrosaccharolyticus, four strains of B. mojavensis, four strains of $B$. subtilis subsp. subtilis, four strains of $B$. thuringiensis, three strains of $B$. siamensis, three strains of B. tequilensis, and 13 strains of other Bacillus spp. Of the remaining 7.3\% of the collection, 10 strains were Sporosarcina globispora, nine strains were Paenibacillus amylolyticus, four strains were $P$. lautus, and 25 strains were from multiple genera. The PGPR strains stored in 30\% glycerol at $-80^{\circ} \mathrm{C}$ were transferred to tryptic soy agar (VWR, Radnor, PA) plates and incubated at $35^{\circ} \mathrm{C}$ for $24 \mathrm{~h}$. Vegetative cells of each strain were suspended in $5 \mathrm{ml}$ of sterile distilled water in $25-\mathrm{ml}$ glass tubes and the concentration was adjusted to $1 \times 10^{7} \mathrm{CFU} / \mathrm{ml}$.

Nematode inoculum. Meloidogyne incognita, originally isolated from an infested field at the Plant Breeding Unit (PBU) at E. V. Smith
Research Center of Auburn University and maintained on corn plants Mycogen 2H723 (Dow AgroScience, Indianapolis, IN) in $500-\mathrm{cm}^{3}$ polystyrene pots in the greenhouse, was used as inoculum in the experiments. Eggs were extracted from corn roots by placing the root system in a $0.625 \% \mathrm{NaOCl}$ solution and agitating the roots for 4 min using a rotary shaker at $120 \mathrm{rpm}$ (Hussey and Barker 1973). Eggs were rinsed with tap water, collected on a $25-\mu \mathrm{m}$-pore sieve, then processed by sucrose centrifugation-flotation at $240 \mathrm{~g}$ for 1 min (Jenkins 1964). For in-vitro tests, $M$. incognita eggs were placed in a modified Baermann funnel (Castillo et al. 2013) on a slide warmer (Model 77) (Marshall Scientific, Brentwood, NH) and incubated at $31^{\circ} \mathrm{C}$ for 5 to 7 days to obtain second-stage juveniles (J2) (Xiang et al. 2014). The $\mathrm{J} 2$ were collected on a $25-\mu \mathrm{m}$-pore sieve, transferred to $1.5-\mathrm{ml}$ microcentrifuge tubes, centrifuged at $5,000 \mathrm{~g}$ for $1 \mathrm{~min}$, rinsed with sterile distilled water, and centrifuged at $5,000 \mathrm{~g}$ for $1 \mathrm{~min}$. The $\mathrm{J} 2$ suspension was adjusted to 30 to $40 \mathrm{~J} 2$ per $10 \mu \mathrm{l}$ of water (Xiang et al. 2014). For trials conducted in the greenhouse and microplot, eggs were enumerated at $40 \times$ magnification using an inverted TS100 Nikon microscope and standardized to 2,000 eggs per cone-tainer or 50,000 eggs per microplot.

Tests in vitro. Tests in vitro were conducted to assess mortality of $M$. incognita $\mathrm{J} 2$ by PGPR strains. PGPR vegetative cell suspensions and $M$. incognita $\mathrm{J} 2$ inocula were prepared as mentioned previously. Ten-microliter nematode suspension containing 30 to $40 \mathrm{M}$. incognita $\mathrm{J} 2$ were added in each well of a $100-\mu 1,96-w e l l$ plate. Ninety microliters of each PGPR bacterial vegetative cell suspension were transferred into each test well of the 96-well plate. Clothianidin plus B. firmus I-1582 (Poncho/VOTiVO) (Bayer CropScience, Raleigh, $\mathrm{NC})$ at $0.7 \mu \mathrm{l} /$ well $(0.424 \mathrm{mg}$ ai/seed $)$ and 1 granule/well of Aldicarb (Temik 15G) (Bayer CropScience, Raleigh, NC) were used as chemical standards. Sterile distilled water was used as the untreated control. Each plate was sealed with parafilm and incubated at room temperature $\left(22.2\right.$ to $\left.25.5^{\circ} \mathrm{C}\right)$ for $48 \mathrm{~h}$. Numbers of live $M$. incognita $\mathrm{J} 2$ were counted and recorded at experiment initiation and $48 \mathrm{~h}$ after 
exposure to the bacterial strains. Viability of $M$. incognita $\mathrm{J} 2$ was determined using the sodium hydroxide technique developed by Xiang and Lawrence (2016). Mortality percentage of $M$. incognita $\mathrm{J} 2$ was calculated using the following equation: [(live $\mathrm{J} 2$ prior to exposure - live $\mathrm{J} 2$ at $48 \mathrm{~h}$ ) / live $\mathrm{J} 2$ prior to exposure] $\times 100$. Each treatment was replicated four times and the in-vitro screening experiment was repeated.

Plant materials. Cotton variety FM1944 GLB2 (Bayer CropScience, Raleigh, NC), known to be susceptible to $M$. incognita (Lawrence et al. 2015), was used for the greenhouse, microplot, and field experiments.

Trials in the greenhouse. Seventy-two PGPR strains were selected from the in-vitro screening for initial evaluation in the greenhouse for their efficacy to reduce nematode population density and promote cotton plant growth. Confidential agreements were signed during this research study and only nine Bacillus strains were available for further testing. These nine strains included one strain of $B$. mojavensis (Bmo3), two strains of B. safensis (Bsa25 and Bsa26), two strains of $B$. subtilis subsp. subtilis (Bsssu2 and Bsssu3), and four strains of B. velezensis (Bve2, Bve12, Bve37, and Bve40). All experiments were conducted at the Plant Science Research Center (PSRC) located at Auburn University, Auburn, AL. Experiments were performed in $150-\mathrm{cm}^{3}$ plastic cone-tainers (Stuewe \& Sons Inc., Tangent, OR) filled with a soil sand mix $(60: 40 \mathrm{v} / \mathrm{v})$. The soil was a Kalmia loamy sand ( $80 \%$ sand, $10 \%$ silt, and $10 \%$ clay) collected from the PBU at E.V. Smith Research Center of Auburn University near Tallassee, AL. Soil was steam pasteurized at $80^{\circ} \mathrm{C}$ for $90 \mathrm{~min}$ and cooled for $24 \mathrm{~h}$, then the steam pasteurizing process was repeated prior to use. Two cotton seeds were planted $1.3 \mathrm{~cm}$ deep in each cone-tainer. One milliliter of bacterial cell suspension $\left(1 \times 10^{7}\right.$ $\mathrm{CFU} / \mathrm{ml}$ ) was added to each seed at planting. For the nematicide controls, cotton seeds were treated with each compound following agricultural industry recommendations: $0.424 \mathrm{mg}$ ai/seed of Clothianidin plus B. firmus I-1582, or $0.15 \mathrm{mg}$ ai/seed of Abamectin (Syngenta, Greensboro, NC), or 1 granule of Aldicarb per seed was applied at planting. All seeds for Clothianidin plus B. firmus I-1582 treatment were treated with a Gustafson table-top seed treater (Bayer CropScience, Research Triangle Park, NC), mixed for $3 \mathrm{~min}$ in a 454-g stainless steel bucket and allowed to air-dry before packaging (Schrimsher et al. 2014). One milliliter of tap water was added to the untreated control seeds. One milliliter of water containing 2,000 M. incognita eggs was pipetted into a 2-cm depression in each cone-tainer at planting and covered with soil. Experiments were arranged in a randomized complete block design (RCBD). Each treatment had five replications and the experiment was repeated. Cotton seedlings were thinned to one per cone-tainer after emergence. Plants were watered as needed. Supplemental light of 1000 watt halide bulbs producing
110,000 lumens was supplied to maintain the day length of $14 \mathrm{~h}$. Greenhouse temperatures ranged from $21^{\circ} \mathrm{C}$ to $35^{\circ} \mathrm{C}$. Experiments were terminated at 45 days after planting (DAP). Plant and nematode measurements were recorded. Plant measurements included plant height $(\mathrm{PH})$ and biomass (Bio) including shoot and root fresh weights (SFW+RFW). Nematode measurements were $M$. incognita eggs per gram of root (eggs/gr).

Trials in the microplots. Six PGPR strains and two mixtures of PGPR strains were evaluated for nematode population development, early plant growth promotion, and yield enhancement on cotton. The strains included $B$. altitudinis strain Bal13, B. mojavensis strain Bmo3, B. subtilis subsp. subtilis strains Bsssu2 and Bsssu3, and B. velezensis strains $\mathrm{Bve} 2$ and Bve12. Mixtures were formed from the best performing strains based on greenhouse studies. The two mixtures were Mixture 1 (Bve2 + Bal13) and Mixture 2 (seeds treated with Abamectin + Bve $2+$ Bal13). The experiments were conducted at the PSRC. Experiments were established in 26.5-liter pots filled with a Kalmia loamy sand collected from the PBU where $M$. incognita and $H$. glycines had not been detected. Experiments were arranged in a RCBD with 6 replications for each treatment and the experiment was repeated. Five cotton seeds were hand-planted at a $1.3-\mathrm{cm}$ depth in a linear pattern to simulate a linear row-foot in the field (Schrimsher et al. 2014). One milliliter of bacterial suspension $\left(1 \times 10^{7} \mathrm{CFU} / \mathrm{ml}\right)$ was applied to each seed at planting. Five milliliters containing 50,000 M. incognita eggs as inoculum were pipetted into each pot at planting. Cotton seeds treated with Clothianidin plus B. firmus I-1582, and Abamectin as previously described, were used as standards. The untreated control included $1 \mathrm{ml}$ of tap water per seed. Each microplot received water at $30 \mathrm{ml} / \mathrm{min}$ by an automated drip irrigation system adjusted throughout the season to run for 15 to $45 \mathrm{~min}$ twice a day, for a total of 450 to $1350 \mathrm{ml}$ of water per microplot per day. At 48 DAP, one representative cotton plant from each microplot was removed for $\mathrm{PH}$ and Bio measurements. The $M$. incognita eggs were extracted from the root system as previously described and enumerated. At plant maturity, 142 DAP, seed cotton was handpicked, and yield was recorded as grams of seed cotton per microplot.

Trials in the field. The same strains and mixtures assessed in the microplot trials were also evaluated in field trials for their effect on early-season nematode population development, plant growth promotion, and yield enhancement in cotton. The experiments were established at PBU and at Prattville Agricultural Research Unit (PARU) in a sandy clay loam soil (64\% sand, $10 \%$ silt, and $26 \%$ clay), Prattville, AL. Both fields were naturally infested with $M$. incognita and numbers of $\mathrm{J} 2$ were just at the detection level of $77 \mathrm{~J} 2 \mathrm{~s}$ per $100 \mathrm{~cm}^{3}$ of soil using the extraction technique as previously described. The experiment was arranged in a RCBD with 5 replications

Table 2. Efficacy of nine Bacillus plant growth-promoting rhizobacteria strains on plant height, biomass, and Meloidogyne incognita eggs/gr on cotton under greenhouse conditions at $45 \mathrm{DAP}^{\mathrm{a}, \mathrm{b}}$

\begin{tabular}{|c|c|c|c|c|c|c|c|c|c|c|c|c|c|c|c|c|}
\hline \multirow[b]{2}{*}{ Treatment } & \multirow[b]{2}{*}{ Scientific name } & \multirow[b]{2}{*}{$\mathbf{P H}^{\mathrm{c}}$} & \multicolumn{4}{|c|}{ Dunnett's $P$} & \multirow[b]{2}{*}{ Bio $^{d}$} & \multicolumn{4}{|c|}{ Dunnett's $P$} & \multirow[b]{2}{*}{ Eggs/gr ${ }^{e}$} & \multicolumn{4}{|c|}{ Dunnett's $P$} \\
\hline & & & $\begin{array}{l}\text { Clothianidin } \\
+ \text { B. firmus }\end{array}$ & Abamectin & Aldicarb & Water & & $\begin{array}{l}\text { Clothianidin } \\
+ \text { B. firmus }\end{array}$ & Abamectin & Aldicarb & Water & & $\begin{array}{l}\text { Clothianidin } \\
+ \text { + B. firmus }\end{array}$ & Abamectin & Aldicarb & Water \\
\hline Bmo3 & B. mojavensis & 11.5 & 0.1391 & 0.0327 & 0.2625 & 0.9944 & 4.5 & 0.0854 & 0.9656 & 0.9929 & 0.9995 & 15,791 & 0.8793 & 0.0178 & $<0.0001$ & 0.9316 \\
\hline Bsa25 & B. safensis & 9.6 & 0.0055 & 0.0009 & 1.0000 & 0.9506 & 6.3 & 0.0212 & 0.4940 & 0.6013 & 0.7049 & 14,311 & 0.6254 & 0.0127 & 0.0001 & 1.0000 \\
\hline Bsa26 & B. safensis & 10.6 & 0.0165 & 0.0024 & 0.8205 & 1.0000 & 4.4 & 0.1320 & 0.9945 & 0.9996 & 1.0000 & 14,789 & 0.6830 & 0.0087 & $<0.0001$ & 0.9978 \\
\hline Bsssu2 & B. subtilis subsp. subtilis & 11.4 & 0.1168 & 0.0262 & 0.3030 & 0.9982 & 3.4 & 0.6943 & 1.0000 & 0.9998 & 0.9903 & 14,821 & 0.8849 & 0.0183 & $<0.0001$ & 0.9268 \\
\hline Bsssu3 & B. subtilis subsp. subtilis & 12.4 & 0.5813 & 0.2230 & 0.0413 & 0.5017 & 4.5 & 0.0523 & 0.8865 & 0.9573 & 0.9905 & 18,163 & 0.8353 & 0.0145 & $<0.0001$ & 0.9605 \\
\hline Bve2 & B. velezensis & 11.5 & 0.1252 & 0.0286 & 0.2865 & 0.9971 & 4.5 & 0.0737 & 0.9470 & 0.9864 & 0.9986 & 7,825 & 1.0000 & 0.2167 & 0.0043 & 0.1225 \\
\hline Bve12 & B. velezensis & 11.5 & 0.1404 & 0.0331 & 0.2603 & 0.9940 & 4.2 & 0.1542 & 0.9979 & 0.9999 & 1.0000 & 15,474 & 0.9701 & 0.0323 & 0.0002 & 0.7773 \\
\hline Bve37 & B. velezensis & 9.0 & 0.0010 & 0.0001 & 1.0000 & 0.6093 & 3.9 & 0.4968 & 1.0000 & 1.0000 & 1.0000 & 21,514 & 0.9613 & 0.0545 & 0.0009 & 0.9733 \\
\hline Bve40 & B. velezensis & 10.8 & 0.0731 & 0.0185 & 0.8411 & 1.0000 & 5.8 & 0.0190 & 0.4675 & 0.5729 & 0.6718 & 27,339 & 0.2840 & 0.0026 & $<0.0001$ & 1.0000 \\
\hline Control & Active ingredient & & & & & & & & & & & & & & & \\
\hline Poncho/Votivo & Clothianidin + B. firmus $\mathrm{I}-1582$ & 14.1 & $\ldots$ & 0.9996 & 0.0023 & 0.0405 & 2.3 & . & 0.6274 & 0.5187 & 0.3105 & 9,702 & ... & 0.3217 & 0.0181 & 0.3400 \\
\hline Avicta & Abamectin & 14.7 & 0.9996 & $\ldots$ & 0.0004 & 0.0070 & 3.2 & 0.6274 & $\ldots$ & 1.0000 & 1.0000 & 1,815 & 0.3517 & $\ldots$ & 0.8740 & 0.0013 \\
\hline Temik & Aldicarb & 9.3 & 0.0023 & 0.0004 & $\ldots$ & 0.8122 & 4.0 & 0.5187 & 1.0000 & $\ldots$ & 1.0000 & 456 & 0.0181 & 0.8401 & 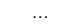 & $<0.0001$ \\
\hline Untreated control & Water & 10.8 & 0.0341 & 0.0061 & 0.7270 & $\ldots$ & 3.8 & 0.2441 & 1.0000 & 1.0000 & $\ldots$ & 15,254 & 0.2687 & 0.0011 & $<0.0001$ & $\ldots$ \\
\hline
\end{tabular}

${ }^{a}$ Greenhouse trials were performed in plastic cone-tainers with mixed pasteurized soil and sand $(60: 40, \mathrm{v} / \mathrm{v})$ for 45 days. The greenhouse trial was repeated twice and data were analyzed in SAS 9.4 using PROC GLIMMIX procedure at a significance level of $\alpha \leq 0.10$. Adjusted $P$ values less than 0.10 indicated a significan effect. Adjusted $P$ values were obtained by analyzing the data according to Dunnett's method. LS-means and adjusted $P$ values were presented in the table.

${ }^{\mathrm{b}} \mathrm{DAP}=$ days after planting.

${ }^{\mathrm{c}} \mathrm{PH}=$ plant height $(\mathrm{cm})$ at $45 \mathrm{DAP}$

${ }^{\mathrm{d}}$ Bio $=$ cotton plant biomass including shoot fresh weight $(\mathrm{g})$ and root fresh weight $(\mathrm{g})$ at 45 DAP

${ }^{\mathrm{e}} \mathrm{Eggs} / \mathrm{gr}=$ M. incognita eggs per gram of root at 45 DAP. 
for each treatment. The field plots were planted in two-row plots, $7 \mathrm{~m}$ long with $0.9-\mathrm{m}$ row spacing. Blocks were separated by a $6-\mathrm{m}$ alley. One hundred cotton seeds were planted in each row with an Almaco plot planter (Almaco, IA). The PGPR strains were standardized to $1 \times$ $10^{7} \mathrm{CFU} /$ seed and applied as in-furrow sprays at 32.5 liter per hectare at planting. Two industry standards were used: seeds treated with Clothianidin plus B. firmus I-1582; or Abamectin as described previously. Tap water applied as an in-furrow spray was the untreated control at 32.5 liter/ha. At $40 \mathrm{DAP}$, four random representative cotton plants were removed from each plot. The same plant growth parameters evaluated in the microplots were also evaluated in the field. Meloidogyne incognita population density was determined by extracting eggs from four root systems per plot. Cotton was harvested mechanically with a cotton picker (Deere \& Company, Moline, IL) at plant maturity which was near 150 DAP and seed cotton yield was recorded.

Statistical analysis. Data collected from in-vitro, greenhouse, microplot, and field trials were analyzed in SAS 9.4 (SAS Institute, Cary, NC) using the PROC GLIMMIX procedure. Dependent variables included $\mathrm{J} 2$ mortality, PH, Bio, $M$. incognita eggs/gr, and yield. Fixed effects were PGPR strains or nematicides treatments and the random effects included replication, test repeat, and location. Student panels were generated to determine the normality of the residuals. The $\mathrm{PH}, \mathrm{Bio}$, and eggs/gr data required a log-normal distribution transformation to satisfy the normal assumptions. LS-means were compared between the treatments, chemical standards Clothianidin plus B. firmus I-1582, Abamectin, Aldicarb, and the untreated control by Dunnett's method at significance levels of $P \leq 0.05$ or $P \leq 0.10$.

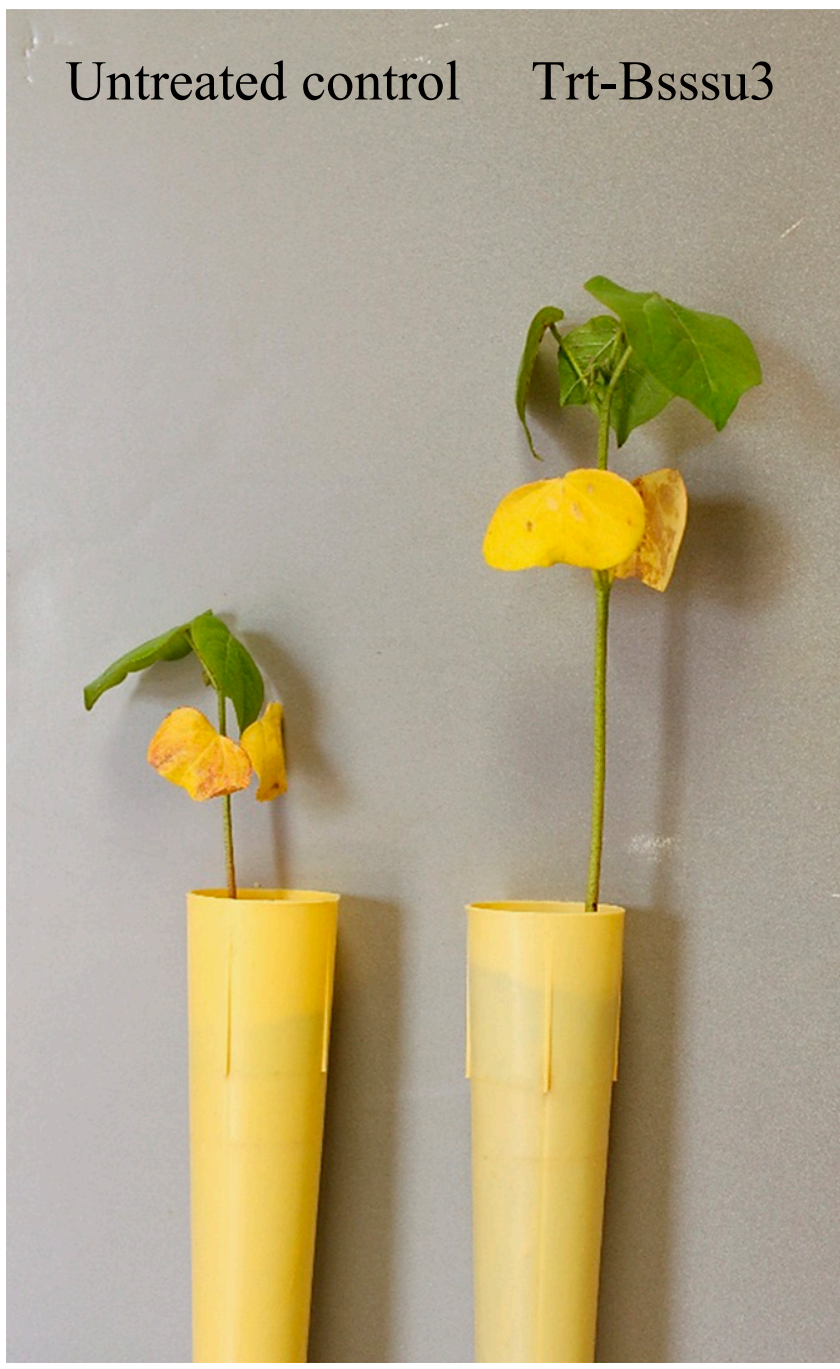

Fig. 1. Cotton plant height was increased from greenhouse trials at 45 DAP. Untreated control (left) and treatment with strain Bacillus subtilis subsp. subtilis Bsssu3 (right).
The LS-means are presented in the tables and adjusted $P$ values are presented for statistical differences.

\section{Results}

Tests in vitro. The mortality percentage of $M$. incognita $\mathrm{J} 2$ ranged from 0.0 to $100 \%$ for the PGPR strains (662), with an average of $39 \%$. Data presented are the results of 212 strains (33\% of 662 strains) that had a greater percent mortality of $M$. incognita $\mathrm{J} 2$ than the untreated control (Table 1). Among all PGPR strains, 33\% caused a significantly greater level of mortality of $M$. incognita $\mathrm{J} 2$ than the untreated control, $19 \%$ produced a significantly greater level of mortality percentage than the biological standard Clothianidin plus $B$. firmus $\mathrm{I}-1582$, and $34 \%$ resulted in a statistically similar mortality percentage to Aldicarb $(P \leq 0.05)$. Among all the strains, Bacillus spp. was the major genus initiating greater mortality percentage when compared with the other genera.

Trials in the greenhouse. In evaluations conducted in the greenhouse, plant height differences were observed (Table 2). Strain $B$. subtilis subsp. subtilis Bsssu3 significantly increased plant height compared with Aldicarb $(P \leq 0.10)$ (Fig. 1). Strain Bsssu3 was the only strain not different from the Abamectin control; all other plants were shorter (Table 2). Strains B. mojavensis Bmo3, B. subtilis subsp. subtilis Bsssu2, B. subtilis subsp. subtilis Bssu3, B. velezensis Bve2, and $B$. velezensis Bve12 were not different from the Clothianidin plus $B$. firmus I-1582 control with respect to plant height. Strains $B$. mojavensis Bmo3, B. safensis Bsa25, B. subtilis subsp. subtilis Bsssu3, and B. velezensis Bve2 (Fig. 2) and Bve40 significantly increased plant

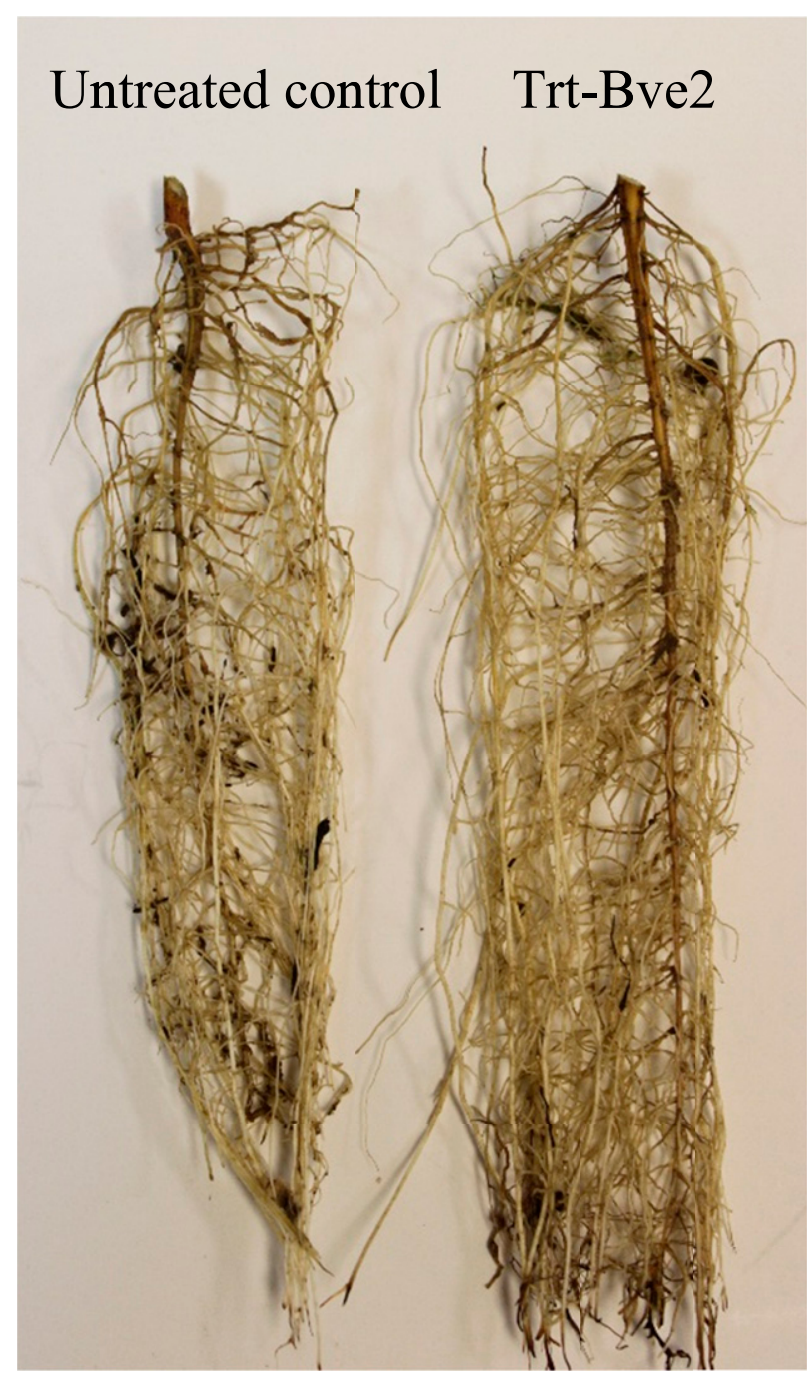

Fig. 2. Cotton roots from greenhouse trials at 45 DAP. Untreated control (left) and treatment with strain Bacillus velezensis Bve2 (right). 
biomass compared with the standard Clothianidin plus $B$. firmus I-1582 at 45 DAP $(P \leq 0.10)$ (Table 2). All Bacillus strains supported similar numbers of $M$. incognita eggs/gr at $45 \mathrm{DAP}$ as compared with the water control. None of the tested Bacillus strains reduced $M$. incognita eggs/gr similarly to the chemical standard Aldicarb. Bacillus velezensis strain Bve2 suppressed $M$. incognita eggs/gr at a level statistically equivalent to the Abamectin control (Table 2). Further, all nine Bacillus PGPR strains tested sustained levels of nematode eggs/ gr statistically equivalent to the biological standard Clothianidin plus B. firmus I-1582 (Table 2).

Trials in microplots. None of the PGPR strains tested significantly affected either plant height or biomass in microplot tests 48 DAP as compared with the controls $(P \leq 0.10)$ (Table 3$)$. Plant heights ranged from 51.2 to $38.7 \mathrm{~cm}$ and biomass ranged from 108.0 to $58.5 \mathrm{~g}$. In the microplot studies, $M$. incognita eggs/gr were reduced by $B$. mojavensis strain $\mathrm{Bmo3}, B$. subtilis subsp. subtilis strain Bsssu3, B. velezensis strain Bve2, and Mixture 2 (Abamectin + Bve2 (B. velezensis) + Bal13 (B. altitudinis) $)$ at 48
DAP compared with the untreated control $(P \leq 0.10)$ (Table 3$)$. The $M$. incognita eggs/gr were statically similar to those recovered from Clothianidin plus B. firmus I-158. Strain Bve12 supported more $M$. incognita eggs/gr than the Abamectin standard $(P \leq 0.05)$. At harvest, microplot yields ranged from 231 to $172 \mathrm{~g}$ per plot with no statistical differences between any of the biological or chemical treatments. The B. velezensis strain Bve12 resulted in the highest seed-cotton yield followed by the Mixture 2 and $B$. velezensis strain Bve2. These yields were statistically similar to the Clothianidin plus B. firmus I-158 and the Abamectin standards (Table 3).

Trials in the field. None of the PGPR strains tested significantly affected either plant height or biomass in field trials 40 DAP as compared with the controls $(P \leq 0.10)$ (Table 4$)$. Plant heights ranged from 25.4 to $19.9 \mathrm{~cm}$ and biomass ranged from 81.8 to $50.0 \mathrm{~g}$. The B. mojavensis strain Bmo3 and Mixture 2 (Abamectin + Bve2 + Bal13) significantly reduced $M$. incognita eggs/gr on cotton at 40 DAP compared with untreated control $(P \leq 0.10)$, which was similar

Table 3. Effect of six plant growth-promoting rhizobacteria strains and two mixtures on cotton plant height, biomass, Meloidogyne incognita eggs/gr at 48 DAP, and cotton yield in microplot trials at $142 \mathrm{DAP}^{\mathrm{a}}$

\begin{tabular}{|c|c|c|c|c|c|c|c|c|c|c|c|c|c|c|c|c|c|}
\hline \multirow[b]{3}{*}{ Treatment } & \multirow[b]{3}{*}{ Scientific name } & \multirow[b]{3}{*}{$\mathbf{P H}^{\mathrm{c}}$} & \multicolumn{3}{|c|}{48 DAP $^{b}$} & \multirow[b]{3}{*}{ Bio $^{d}$} & \multicolumn{3}{|c|}{48 DAP } & \multirow[b]{3}{*}{ Eggs/gre } & \multicolumn{3}{|c|}{48 DAP } & \multirow[b]{3}{*}{ Yield $^{\mathrm{P}}$} & \multicolumn{3}{|c|}{142 DAP } \\
\hline & & & \multicolumn{3}{|c|}{ Dunnett's $P$ versus $(P \leq 0.05)$} & & \multicolumn{3}{|c|}{ Dunnett's $P$ versus $(P \leq 0.05)$} & & \multicolumn{3}{|c|}{ Dunnett's $P$ versus $(P \leq 0.05)$} & & \multicolumn{3}{|c|}{ Dunnett's $P$ versus $(P \leq 0.05)$} \\
\hline & & & $\begin{array}{l}\text { Clothianidin } \\
+ \text { B. firmus }\end{array}$ & Abamectin & Water & & $\begin{array}{l}\text { Clothianidin } \\
+ \text { B. firmus }\end{array}$ & Abamectin & Water & & $\begin{array}{l}\text { Clothianidin } \\
+ \text { B. firmus }\end{array}$ & Abamectin & Water & & $\begin{array}{l}\text { Clothianidin } \\
+ \text { B. firmus }\end{array}$ & Abamectin & Water \\
\hline Bal13 & B. altitudinis & 46.5 & 1.0000 & 0.9932 & 0.9874 & 95.1 & 1.0000 & 1.0000 & 0.9965 & 872 & 0.9933 & 0.1524 & 0.5332 & 185 & 0.9994 & 1.0000 & 1.0000 \\
\hline Bmo3 & B. mojavensis & 51.2 & 0.9988 & 0.6473 & 0.5630 & 108.0 & 0.8148 & 0.8738 & 0.6335 & 212 & 0.9983 & 0.8894 & 0.0459 & 199 & 1.0000 & 0.9980 & 0.9975 \\
\hline Bsssu2 & B. subtilis subsp. subtilis & 38.7 & 0.6070 & 0.9974 & 1.0000 & 58.5 & 1.0000 & 0.9997 & 1.0000 & 409 & 1.0000 & 0.4690 & 0.1835 & 178 & 0.9949 & 1.0000 & 1.0000 \\
\hline Bsssu3 & B. subtilis subsp. subtilis & 42.5 & 0.9646 & 1.0000 & 1.0000 & 65.3 & 0.9978 & 0.9928 & 1.0000 & 299 & 0.9730 & 0.9779 & 0.0231 & 190 & 0.9999 & 0.9999 & 0.9999 \\
\hline Bve2 & B. velezensis & 48.5 & 1.0000 & 0.9196 & 0.7918 & 85.4 & 0.9977 & 0.9995 & 0.9700 & 163 & 0.9928 & 0.9398 & 0.0340 & 215 & 1.0000 & 0.9494 & 0.9438 \\
\hline Bve12 & B. velezensis & 43.0 & 0.9810 & 1.0000 & 1.0000 & 67.4 & 1.0000 & 0.9999 & 1.0000 & 1,357 & 0.7459 & 0.0354 & 0.9340 & 231 & 0.9992 & 0.7555 & 0.7434 \\
\hline Mixture $1^{g}$ & & 43.8 & 0.9950 & 1.0000 & 0.9996 & 72.5 & 0.9996 & 0.9981 & 1.0000 & 913 & 1.0000 & 0.3256 & 0.2837 & 197 & 1.0000 & 0.9991 & 0.9988 \\
\hline Mixture $2^{g}$ & & 46.3 & 1.0000 & 0.9950 & 0.9687 & 65.9 & 1.0000 & 0.9999 & 1.0000 & 361 & 0.9884 & 0.9549 & 0.0301 & 229 & 0.9997 & 0.7915 & 0.7799 \\
\hline Control & Active ingredient & & & & & & & & & & & & & & & & \\
\hline Poncho/Votivo & $\begin{array}{l}\text { Clothianidin }+B \text {. } \\
\text { firmus I-1582 }\end{array}$ & 47.8 & $\ldots$ & 0.9575 & 0.9003 & 66.9 & $\ldots$ & 1.0000 & 1.0000 & 436 & $\ldots$ & 0.5022 & 0.1667 & 208 & $\ldots$ & 0.9829 & 0.9802 \\
\hline Avicta & Abamectin & 42.3 & 0.9575 & $\ldots$ & 1.0000 & 81.3 & 1.0000 & $\ldots$ & 1.0000 & 69 & 0.5022 & $\ldots$ & 0.0022 & 173 & 0.9829 & $\ldots$ & 1.0000 \\
\hline Untreated control & Water & 42.2 & 0.9494 & 1.0000 & $\ldots$ & 93.3 & 1.0000 & 1.0000 & $\ldots$ & 1,551 & 0.1667 & 0.0022 & $\ldots$ & 172 & 0.9802 & 1.0000 & $\ldots$ \\
\hline
\end{tabular}

${ }^{a}$ Microplot trials were performed in 26.5 liter pots with a kalmia loamy sand soil. The microplot trial was repeated and analyzed in SAS 9.4 using PROC GLIM-

MIX procedure at a significance level of $\alpha \leq 0.05$. Adjusted $P$ values less than 0.05 indicated a significant effect. Adjusted $P$ values were obtained by analyzing data according to Dunnett's method. LS-means and adjusted $P$ values were presented in the table.

${ }^{\mathrm{b}} \mathrm{DAP}=$ days after planting.

${ }^{\mathrm{c}} \mathrm{PH}=$ plant height $(\mathrm{cm})$ at $48 \mathrm{DAP}$

${ }^{\mathrm{d}}$ Bio $=$ cotton plant biomass including shoot fresh weight $(\mathrm{g})$ and root fresh weight $(\mathrm{g})$ at 48 DAP

${ }^{\mathrm{e}} \mathrm{Eggs} / \mathrm{gr}=M$. incognita eggs per gram of root at $48 \mathrm{DAP}$.

$\mathrm{f}$ Yield $=$ grams of seed cotton yield handpicked at harvest.

g Mixture 1 = strain Bve2 + strain Bal13; Mixture 2 = Abamectin + strain Bve2 + strain Bal13.

Table 4. Efficacy of six plant growth-promoting rhizobacteria strains and two mixtures on plant height, plant biomass, and Meloidogyne incognita eggs/gr at 40 $\mathrm{DAP}$, and yield of cotton in a field production system at $150 \mathrm{DAP}^{\mathrm{a}}$

\begin{tabular}{|c|c|c|c|c|c|c|c|c|c|c|c|c|c|c|c|c|c|}
\hline \multirow[b]{3}{*}{ Treatment } & \multirow[b]{3}{*}{ Scientific name } & \multirow[b]{3}{*}{$\mathbf{P H}^{\mathrm{c}}$} & \multicolumn{3}{|c|}{$40 \mathrm{DAP}^{\mathrm{b}}$} & \multirow[b]{3}{*}{ Bio $^{d}$} & \multicolumn{3}{|c|}{40 DAP } & \multirow[b]{3}{*}{ Eggs/gr ${ }^{\mathrm{e}}$} & \multicolumn{3}{|c|}{40 DAP } & \multirow[b]{3}{*}{ Yield $^{\mathrm{r}}$} & \multicolumn{3}{|c|}{150 DAP } \\
\hline & & & \multicolumn{3}{|c|}{ Dunnett's $P$ versus $(P \leq 0.05)$} & & \multicolumn{3}{|c|}{ Dunnett's $P$ versus $(P \leq 0.05)$} & & \multicolumn{3}{|c|}{ Dunnett's $P$ versus $(P \leq 0.05)$} & & \multicolumn{3}{|c|}{ Dunnett's $P$ versus $(P \leq 0.10)$} \\
\hline & & & $\begin{array}{l}\text { Clothianidin } \\
+ \text { B. firmus }\end{array}$ & Abamectin & Water & & $\begin{array}{l}\text { Clothianidin } \\
+ \text { B. firmus }\end{array}$ & Abamectin & Water & & $\begin{array}{l}\text { Clothianidin } \\
+ \text { B. firmus }\end{array}$ & Abamectin & Water & & $\begin{array}{l}\text { Clothianidin } \\
+ \text { B. firmus }\end{array}$ & Abamectin & Water \\
\hline Bal13 & B. altitudinis & 19.9 & 0.8818 & 0.9129 & 0.9793 & 58.9 & 0.9973 & 0.9999 & 1.0000 & 1,747 & 0.9961 & 0.9998 & 0.6523 & 3,902 & 1.0000 & 0.5795 & 0.4826 \\
\hline Bmo3 & B. mojavensis & 25.4 & 0.9997 & 0.9992 & 0.9879 & 81.8 & 0.9997 & 0.9952 & 0.9853 & 349 & 0.1023 & 0.6717 & 0.0126 & 4,235 & 0.9974 & 0.9823 & 0.1278 \\
\hline Bsssu2 & B. subtilis subsp. subtilis & 22.6 & 1.0000 & 1.0000 & 1.0000 & 60.3 & 0.9989 & 1.0000 & 1.0000 & 1,358 & 0.8676 & 1.0000 & 0.3360 & 4,089 & 1.0000 & 0.8462 & 0.2211 \\
\hline Bsssu3 & B. subtilis subsp. subtilis & 23.6 & 1.0000 & 1.0000 & 1.0000 & 67.0 & 1.0000 & 1.0000 & 1.0000 & 2,569 & 0.9998 & 0.5922 & 1.0000 & 4,204 & 0.9993 & 0.9622 & 0.1313 \\
\hline Bve2 & B. velezensis & 23.0 & 1.0000 & 1.0000 & 1.0000 & 65.5 & 1.0000 & 1.0000 & 1.0000 & 1,416 & 0.8906 & 1.0000 & 0.3486 & 4,415 & 0.9096 & 1.0000 & 0.0528 \\
\hline Bve12 & B. velezensis & 20.7 & 0.9681 & 0.9807 & 0.9983 & 50.0 & 0.9152 & 0.9749 & 0.9905 & 2,805 & 0.9867 & 0.3755 & 1.0000 & 4,396 & 0.9398 & 0.9999 & 0.0499 \\
\hline Mixture $1^{g}$ & & 20.5 & 0.9507 & 0.9681 & 0.9960 & 51.1 & 0.9351 & 0.9833 & 0.9944 & 2,191 & 1.0000 & 0.9172 & 0.9706 & 4,091 & 1.0000 & 0.8702 & 0.2403 \\
\hline Mixture $2^{g}$ & & 23.0 & 1.0000 & 1.0000 & 1.0000 & 77.9 & 1.0000 & 0.9997 & 0.9981 & 699 & 0.9364 & 0.9438 & 0.0454 & 3,582 & 0.9337 & 0.1532 & 0.9356 \\
\hline Control & Active ingredient & & & & & & & & & & & & & & & & \\
\hline Poncho/Votivo & $\begin{array}{l}\text { Clothianidin + } \\
\quad \text { B. firmus I-1582 }\end{array}$ & 23.8 & $\ldots$ & 1.0000 & 1.0000 & 71.9 & $\ldots$ & 1.0000 & 1.0000 & 2,232 & ... & 0.8926 & 0.9807 & 3,993 & $\ldots$ & 0.7291 & 0.3523 \\
\hline Avicta & Abamectin & 23.5 & 1.0000 & & 1.0000 & 67.8 & 1.0000 & $\ldots$ & 1.0000 & 1,419 & 0.8926 & .. & 0.3509 & 4,563 & 0.7276 & & 0.0199 \\
\hline Untreated control & Water & 22.7 & 1.0000 & 1.0000 & $\ldots$ & 65.4 & 1.0000 & 1.0000 & $\ldots$ & 2,889 & 0.9809 & 0.3521 & $\ldots$ & 3,186 & 0.3503 & 0.0198 & $\ldots$ \\
\hline
\end{tabular}

${ }^{\text {a }}$ Field trials were performed in two naturally infested fields in AL. Data were combined and analyzed in SAS 9.4 using PROC GLIMMIX procedure at significance level of $\alpha \leq 0.05$ for PH, Bio, and Eggs/gr and at a significance level of $\alpha \leq 0.10$ for cotton yield. Adjusted $P$ values less than 0.05 or 0.10 indicated a significant effect. Adjusted $P$ values were obtained by analyzing data according to Dunnett's method. LS-means and adjusted $P$ values were presented in the table

${ }^{\mathrm{b}} \mathrm{DAP}=$ days after planting.

${ }^{c} \mathrm{PH}=$ plant height $(\mathrm{cm})$ at 40 DAP

${ }^{\mathrm{d}} \mathrm{Bio}=$ cotton plant biomass including shoot fresh weight $(\mathrm{g})+$ root fresh weight $(\mathrm{g})$ at 40 DAP

${ }^{\mathrm{e}} \mathrm{Eggs} / \mathrm{gr}=$ M. incognita eggs per gram of root at $40 \mathrm{DAP}$.

${ }^{\mathrm{f}}$ Cotton yield $=$ seed cotton yield in kilogram/hectare at $150 \mathrm{DAP}$.

g Mixture 1 = strain Bve2 + strain Bal13; Mixture 2 = Abamectin + strain Bve2 + strain Bal13. 
to Clothianidin plus B. firmus $\mathrm{I}-1582$ and Abamectin standards $(P \leq$ 0.10) (Table 4). The B. velezensis strains Bve12 (Fig. 3) and Bve2 (Fig. 4) significantly increased seed-cotton yield compared with untreated control, and was similar to Clothianidin plus B. firmus I-1582 and Abamectin standards $(P \leq 0.10)$ (Table 4$)$.

\section{Discussion}

The results indicated that among all the PGPR strains, 33\% caused a significantly greater level of mortality of $M$. incognita $\mathrm{J} 2$ than the untreated control and 34\% caused statistically similar mortality to the level caused by Aldicarb $(P \leq 0.05)$. Bacillus spp. was the primary genus causing greater mortality percentage of $M$. incognita $\mathrm{J} 2$ in the in-vitro tests. Further greenhouse, microplot, and field trials confirmed that specific strains of the Bacillus PGPR suppressed the population density of $M$. incognita in the greenhouse, microplot, and field evaluation systems, and increased seed cotton yield.

In vitro screening of the PGPR strains indicated that Bacillus spp. caused greater mortality of $M$. incognita $\mathrm{J} 2$ in vitro than other genera. Some strains of specific Bacillus spp. were previously reported to have nematicidal activity against plant-parasitic nematodes on different host plants. Kloepper et al. (1992) reported that B. megaterium strain 1758 and $B$. pumilus strain 163 significantly reduced galls of $M$. incognita and cysts of $H$. glycines on soybean. Payne (1993) stated in a Bt patent that some strains of $B$. thuringiensis had nematicidal activity against nematodes including plant-parasitic nematodes $M$. incognita and Aphelenchus avenae. Siddiqui et al. (2001) reported that a B. subtilis strain isolated from the rhizosphere of Helianthus annuus had nematicidal activity on $M$. javanica in mungbean. Burkett-Cadena et al. (2008) found that B. subtilis strain GB03 and B. velezensis strain GB99 (BioYield, Gustafson LLC, Plano TX, USA) induced significant reductions in $M$. incognita eggs/gr, juvenile nematodes per $\mathrm{cm}^{3}$ of soil, and galls per plant on tomato. Bacillus firmus, the active ingredient of BioNem-WP (AgroGreen, Israel) was reported to control rootknot nematode on vegetables (Hallmann et al. 2009). In our study, we also found the specific strains of the species B. pumilus, $B$. thuringiensis, B. subtilis, B. velezensis, and $B$. firmus had nematicidal activity on $M$. incognita in our tests. In our trials, 17 different Bacillus species and subspecies, including B. altitudinis, B. aryabhattai, B. cereus, B. galliciensis, B. lentus, B. methylotrophicus, B. mojavensis, B. mycoides, B. psychrosaccharolyticus, B. safensis, B. siamensis, B. simplex, B. subtilis subsp. inaquosorum, $B$. subtilis subsp. subtilis, $B$. tequilensis,

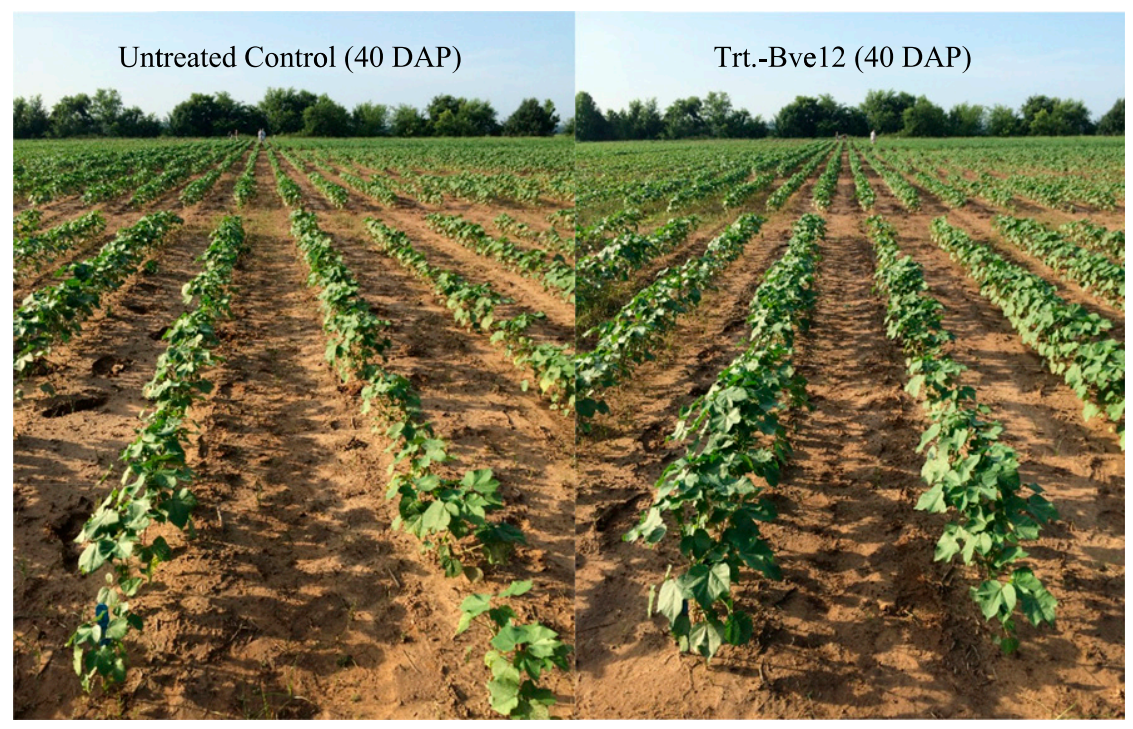

Fig. 3. Cotton plants in Plant Breeding Unit (PBU) at 40 DAP. Untreated control (left) and treatment with strain Bacillus velezensis Bve12 (right).

Untreated Control (90 DAP) Trt.-Bve2 (90 DAP)

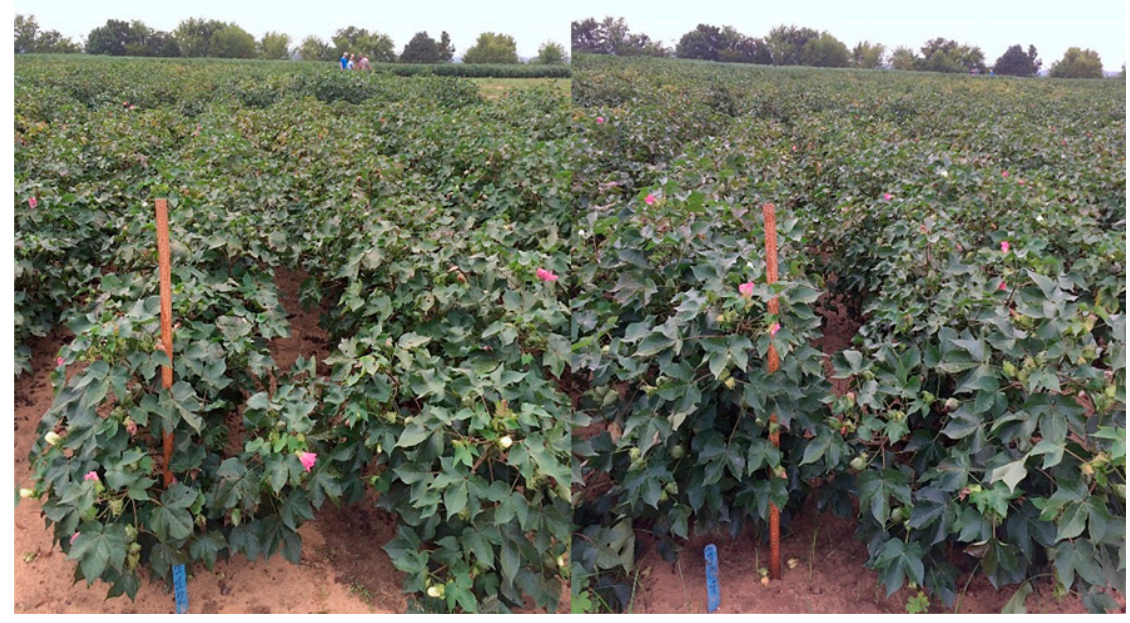

Fig. 4. Cotton plants in PBU at 90 DAP. Untreated control (left) and treatment with strain Bacillus velezensis Bve2 (right). 
B. toyonensis, B. weihenstephanensis, were found to have antagonistic activity against $M$. incognita. This is the first documentation of antagonistic activity by these Bacillus spp. to $M$. incognita.

The results from the greenhouse, microplot, and field experiments indicated that Bve2 (B. velezensis), Bmo3 (B. mojavensis), and Mixture 2 (Abamectin + Bve2 + Bal13) were relatively consistent in reduction of M. incognita eggs/gr, and B. velezensis strains Bve2 and Bve12 increased early plant growth and enhanced cotton yield. Many reports have shown that specific strains of PGPR or mixtures of PGPR strains can promote plant growth, reduce plant disease, and enhance yield with multiple hosts under greenhouse, microplot, or field conditions (Castillo et al. 2013; Jetiyanon and Kloepper 2002; Liu et al. 2016; Raupach and Kloepper 1998; Wei et al. 1996; Yan et al. 2002). Castillo et al. (2013) evaluated PGPR B. firmus GB-126 combined with Paecilomyces lilacinus 251 in commercial formulations in greenhouse, microplot, and field trials for the management of Rotylenchulus reniformis in cotton and reported that $R$. reniformis population density was decreased when exposed to $B$. firmus and $P$. lilacinus in the greenhouse, in the microplot at midseason, and in the field at harvest. Liu et al. (2016) found that specific PGPR strains Bve12 and Bve15 (B. velezensis), and Bmo3 (B. mojavensis), strain mixture-1 (Bve12 + Bmo3 + Lysinibacillus macrolides strain Lma1 + Bve15) and mixture-2 (mixture-1 + B. safensis strain $\mathrm{Bsa} 27+$ B. pumilus strain $\mathrm{Bpu} 6+$ B. velezensis strain Bve40) used in our studies also reduced black rot on Chinese cabbage caused by Xanthomonas campestris pv. campestris and increased marketable yield. Our studies added additional information to their findings that PGPR strains and mixtures of PGPR strains can promote earlyseason plant growth, increase yield, and reduce nematode numbers.

Mode of action of some PGPR strains has been studied. Mendoza et al. (2008) reported that mortality of sedentary and migratory endoparasitic nematodes $M$. incognita, Radopholus similis, and Ditylenchus dipsaci by $B$. firmus in in-vitro tests were closely associated with the production of bioactive secondary metabolites by the bacteria. Huang et al. (2010) demonstrated that PGPR strain B. megaterium YMF 3.25 significantly inhibited hatching of nematode eggs and reduced infection of $M$. incognita through production of nematicidal volatiles. They also confirmed that the nematicidal volatiles produced by the bacterium were mainly benzeneacetaldehyde, 2-nonanone, decanal, 2-undecanone, and dimethyl disulphide, which were active against juveniles and eggs at the concentration of $0.5 \mathrm{mmol}$, and that six other compounds also contributed to the nematicidal efficacy (Huang et al. 2010). Peng et al. (2011) tested three B. thuringiensis nematicidal crystal proteins Cry6Aa, Cry5Ba, and Cry55Aa against $M$. incognita and found that the combination of Cry6Aa and Cry55Aa caused significant synergistic toxicity against $M$. incognita. These reports indicated that the mode of action of the Bacillus PGPR strains with nematicidal activity is likely related to the production of bioactive secondary metabolites. Further research is needed to address the modes of action of the PGPR strains with nematicidal activity on M. incognita.

ISR elicited by Bacillus spp. against plant-parasitic nematodes is another important mode of action. Kloepper et al. (2004) summarized the published results and reported that specific strains of the species $B$. velezensis, B. subtilis, B. pasteurii, B. cereus, B. pumilus, B. mycoides, and $B$. sphaericus elicit significant reductions in the incidence or severity of various diseases, including root-knot nematode. The bacterial strains $B$. sphaericus B43 and Rhizobium etli G12 were reported to induce systemic resistance toward $M$. incognita on tomato as expressed in reduced juvenile penetration in the responder roots (Hauschild et al. 2000; Schäfer et al. 2006; Sikora et al. 2007). Bacillus mojavensis strain Bmo3 and B. velezensis strain Bve12, which were previously found to induce systemic resistance to black rot disease on Chinese cabbage and increase yield (Liu et al. 2016) were also found to reduce $M$. incognita population density and increase yield on cotton in our study. It is possible that the reduced $M$. incognita population density observed in our cotton trials could have resulted from induction of ISR by the PGPR strains Bmo3, Bve2, and Mixture 2 (Abamectin + Bve2 + Bal13), but further work is needed to test this.

In summary, B. mojavensis strain $\mathrm{Bmo3}$, B. velezensis strains Bve2 and Bve12, and Mixture 2 (Abamectin + Bve2 + Bal13) are promising biological control agents which should be further evaluated for potential use against plant-parasitic nematodes. These biological strains could potentially be alternatives to chemical nematicides or combined with chemical nematicides for the management of $M$. incognita.

\section{Acknowledgment}

We thank Cotton Inc. for its support of this research.

\section{Literature Cited}

Askary, T. H. 2015. Limitations, research needs and future prospects in the biological control of phytonematodes. Page 446 in: Biocontrol agents of phytonematodes. T. H. Askary, and P. R. P. Martinelli, eds. CAB International, Wallingford, UK.

Burkett-Cadena, M., Kokalis-Burelle, N., Lawrence, K. S., Van Santen, E., and Kloepper, J. W. 2008. Suppressiveness of root-knot nematodes mediated by rhizobacteria. Biol. Control 47:55-59.

Castillo, J. D., Lawrence, K. S., and Kloepper, J. W. 2013. Biocontrol of the reniform nematode by Bacillus firmus GB-126 and Paecilomyces lilacinus 251 on cotton. Plant Dis. 97:967-976.

Creech, R. G., Jenkins, J. N., Tang, B., Lawrence, G. W., and McCarty, J. C. 1995. Cotton resistance to root-knot nematode: I. Penetration and reproduction. Crop Sci. 35:365-368

Hallmann, J., Davies, K. G., and Sikora, R. A. 2009. Biological control using microbial pathogens, endophytes and antagonists. Pages 380-411 in: Root-knot nematode. R. N. Perry, M. Moens, and J. L. Starr, eds. CAB International, Wallingford, UK.

Hauschild, R., Hallmann, J., and Sikora, R. A. 2000. Fusarium oxysporum and Meloidogyne incognita on tomato can be controlled by antagonistic rhizobacteria. Commun. Agric. Appl. Biol. Sci. 65:527-528.

Huang, Y., Xu, C. K., Ma, L., Zhang, K. Q., Duan, C. Q., and Mo, M. H. 2010 Characterization of volatiles produced from Bacillus megaterium YFM3.25 and their nematicidal activity against Meloidogyne incognita. Eur. J. Plant Pathol. 126:417-422.

Hussey, R. S., and Barker, K. R. 1973. A comparison of methods of collecting inocula of Meloidogyne spp., including a new technique. Plant Dis. Rep. 57:1025-1028.

Jenkins, W. 1964. A rapid centrifugal-floatation technique for separating nematodes from soil. Plant Dis. Rep. 48:692.

Jetiyanon, K., and Kloepper, J. W. 2002. Mixtures of plant growth-promoting rhizobacteria for induction of systemic resistance against multiple plant diseases. Biol. Control 24:285-291.

Kavitha, J., Jonathan, E. I., and Umamaheswari, R. 2007. Field application of Pseudomonas fluorescens, Bacillus subtilis and Trichoderma viride for the control of Meloidogyne incognita (Kofoid and White) Chitwood on sugarbeet. J. Biol. Control. 21:211-215.

Keren-Zur, M., Antonov, J., Bercovitz, A., Feldman, K., Husid, A., Kenan, G., Markov, N., and Rebhun, M. 2000. Bacillus firmus formulations for the safe control of root-knot nematodes. Pages 47-52 in: Proc. of the Brighton Crop Prot. Conf. on Pests and Dis. Vol. 2A.

Khan, M. R., and Akram, M. 2000. Effects of certain antagonistic fungi and rhizobacteria on wilt disease complex of tomato caused by Meloidogyne incognita and Fusarium oxysporum f. sp. lycopersici. Nematol. Mediterr. 28:139-144.

Kiewnick, S., and Sikora, R. A. 2006. Biological control of the root-knot nematode Meloidogyne incognita by Paecilomyces lilacinus strain 251. Biol. Control 38: 179-187.

Kloepper, J. W., Rodríguez-Kábana, R., McInroy, J. A., and Young, R. W. 1992. Rhizosphere bacteria antagonistic to soybean cyst (Heterodera glycines) and root-knot (Meloidogyne incognita) nematodes: identification by fatty acid analysis and frequency of biological control activity. Plant Soil 139:75-84.

Kloepper, J. W., Ryu, C. M., and Zhang, S. A. 2004. Induced systemic resistance and promotion of plant growth by Bacillus spp. Phytopathology 94:1259-1266.

Krechel, A., Faupel, A., Hallmann, J., Ulrich, A., and Berg, G. 2002. Potatoassociated bacteria and their antagonistic potential towards plant-pathogenic fungi and the plant-parasitic nematode Meloidogyne incognita (Kofoid \& White). Chitwood. Can. J. Microbiol. 48:772-786.

Lawrence, K., Olsen, M., Faske, T., Hutmacher, R., Muller, J., Mario, J., Kemerait, R., Overstreet, C., Price, P., Sciumbato, G., Lawrence, G., Atwell, S., Thomas, S., Koenning, S., Boman, R., Young, H., Woodward, J., and Mehl, H. 2015. Cotton disease loss estimate committee report. Pages 188-190 in: Proc. Beltwide Cotton Conf. 2015. Vol. 1. National Cotton Council, Memphis, TN.

Lawrence, K. S., Lawrence, G. W., Faske, T., Overstreet, C., Wheeler, T., Young, H., Kemerait, B., and Mehl, H. 2016. Beltwide nematode research and education committee 2015 nematode research report cotton varietal and nematicide responses in nematode soils. Pages 113-115 in: Proc. Beltwide Cotton Conf. 2016. Vol. 1. National Cotton Council, Memphis, TN.

Liu, K., Garrett, C., Fadamiro, H., and Kloepper, J. W. 2016. Induction of systemic resistance in Chinese cabbage against black rot by plant growth-promoting rhizobacteria. Biol. Control 99:8-13.

Mendoza, A. R., Kiewnick, S., and Sikora, R. A. 2008. In vitro activity of Bacillus firmus against the burrowing nematode Radopholus similis, the root-knot nematode Meloidogyne incognita and the stem nematode Ditylenchus dipsaci. Biocontrol Sci. Technol. 18:377-389. 
Mohammed, S. H., El Saedy, M. A., Enan, M. R., Ibrahim, N. E., Ghareeb, A., and Moustafa, S. A. 2008. Biocontrol efficiency of Bacillus thuringiensis toxins against root-knot nematode, Meloidogyne incognita. J. Cell Mol. Biol. 7:57-66.

Payne, J. M. 1993. Isolates of Bacillus thuringiensis that are active against nematodes. U. S. Pat. No. 5,151,363. Dec 14, 1993.

Peng, D. H., Chai, L. J., Wang, F. S., Zhang, F. J., Ruan, L. F., and Sun, M. 2011. Synergistic activity between Bacillus thuringiensis Cry6Aa and Cry55Aa toxins against Meloidogyne incognita. Microb. Biotechnol. 4:794-798.

Raupach, G. S., and Kloepper, J. W. 1998. Mixtures of plant growth-promoting rhizobacteria enhance biological control of multiple cucumber pathogens. Phytopathology 88:1158-1164.

Robinson, A. F. 2007. Reniform in US cotton: when, where, why, and some remedies. Annu. Rev. Phytopathol. 45:263-288.

Schäfer, K., Silva Fabry, C., and Sikora, R. A. 2006. Molecular investigations of rhizobacteria-induced systemic resistance towards the root-knot nematode Meloidogyne incognita in tomato. Multitrophic interactions in soil. IOBC WPRS Bull. 29:135-140.

Schrimsher, D. W. 2013. The studies of plant host resistance to the reniform nematode in upland cotton and the effects of Bacillus firmus GB-126 on plant-parasitic nematode. M.S. Thesis. Auburn University, Auburn, AL. https://etd.auburn.edu/handle/10415/3562.

Schrimsher, D. W., Lawrence, K. S., Sikkens, R. B., and Weaver, D. B. 2014. Nematicides enhance growth and yield of Rotylenchulus reniformis resistant cotton genotypes. J. Nematol. 46:365-375.

Serfoji, P., Rajeshkumar, S., and Selvaraj, T. 2010. Management of root-knot nematode, Meloidogyne incognita on tomato cv Pusa Ruby. by using vermicompost, AM fungus, Glomus aggregatum and mycorrhiza helper bacterium, Bacillus coagulans. J. Agric. Technol. 6:37-45.

Siddiqui, A. I., Ehetshamul-Haque, S., and Shahid Shaukat, S. 2001. Use of rhizobacteria in the control of root rot-root knot disease complex of mungbean. J. Phytopathol. 149:337-346.

Siddiqui, Z. A., and Husain, S. I. 1991. Studies on the biological control of rootknot nematode. Curr. Nematol. 2:5-6.
Siddiqui, Z. A., and Mahmood, I. 1992. Biological control of root-rot disease complex of chickpea caused by Meloidogyne incognita race 3 and Macrophomina phaseolina. Nematol. Mediterr. 20:199-202.

Siddiqui, Z. A., and Mahmood, I. 1999. Role of bacteria in the management of plant parasitic nematodes: a review. Bioresour. Technol. 69:167-179.

Sikora, R. A. 1988. Interrelationship between plant health promoting rhizobacteria, plant parasitic nematodes and soil microorganisms. Commun. Agric. Appl. Biol. Sci. 53:867-878.

Sikora, R. A., Schäfer, K., and Dababat, A. A. 2007. Modes of action associated with microbially induced in planta suppression of plant-parasitic nematodes. Australas. Plant Pathol. 36:124-134.

Terefe, M., Tefera, T., and Sakhuja, P. K. 2009. Effect of a formulation of Bacillus firmus on root-knot nematode Meloidogyne incognita infestation and the growth of tomato plants in the greenhouse and nursery. J. Invertebr. Pathol. 100:94-99.

Wei, G., Kloepper, J. W., and Tuzun, S. 1996. Induced systemic resistance to cucumber diseases and increased plant growth by plant growth-promoting rhizobacteria under field conditions. Phytopathology 86:221-224.

Wilson, M. J., and Jackson, T. A. 2013. Progress in the commercialization of bionematicides. BioControl 58:715-722

Xiang, N., and Lawrence, K. S. 2016. Optimization of in vitro techniques for distinguishing between live and dead second stage juveniles of Heterodera glycines and Meloidogyne incognita. PLoS One 11:e0154818.

Xiang, N., Lawrence, K. S., Kloepper, J. W., and Mcinroy, J. A. 2014. In vitro screening of biological control agents on Meloidogyne incognita. Pages 258-260 in: Proc. Beltwide Cotton Conf. 2014. Vol. 1. National Cotton Council, Memphis, TN.

Yan, Z. N., Reddy, M. S., Ryu, C. M., McInroy, J. A., Wilson, M., and Kloepper, J. W. 2002. Induced systemic protection against tomato late blight elicited by plant growth-promoting rhizobacteria. Phytopathology 92:1329-1333.

Zuckerman, B. M., Dicklow, M. B., and Acosta, N. 1993. A strain of Bacillus thuringiensis for the control of plant-parasitic nematodes. Biocontrol Sci. Technol. 3:41-46. 